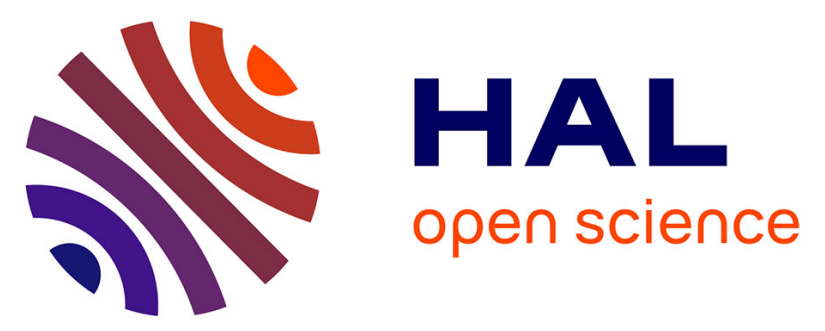

\title{
Harnessing Atomic Layer Deposition and Diffusion to Spatially Localize Rare-Earth Ion Emitters
}

Alban Ferrier, Nao Harada, Marion Scarafagio, Emrick Briand, Jean-Jacques

Ganem, Ian Vickridge, Antoine Seyeux, Philippe Marcus, Diana Serrano, Philippe Goldner, et al.

\section{To cite this version:}

Alban Ferrier, Nao Harada, Marion Scarafagio, Emrick Briand, Jean-Jacques Ganem, et al.. Harnessing Atomic Layer Deposition and Diffusion to Spatially Localize Rare-Earth Ion Emitters. Journal of Physical Chemistry C, 2020, 124 (36), pp.19725-19735. 10.1021/acs.jpcc.0c04019 . hal-02994689

\section{HAL Id: hal-02994689 \\ https://hal.science/hal-02994689}

Submitted on 29 Nov 2021

HAL is a multi-disciplinary open access archive for the deposit and dissemination of scientific research documents, whether they are published or not. The documents may come from teaching and research institutions in France or abroad, or from public or private research centers.
L'archive ouverte pluridisciplinaire HAL, est destinée au dépôt et à la diffusion de documents scientifiques de niveau recherche, publiés ou non, émanant des établissements d'enseignement et de recherche français ou étrangers, des laboratoires publics ou privés. 


\section{C: Plasmonics; Optical, Magnetic, and Hybrid Materials}

\section{Harnessing Atomic Layer Deposition and Diffusion to Spatially Localize Rare-Earth Ion Emitters}

Alban Ferrier, Nao Harada, Marion Scarafagio, Emrick Briand, jean-jacques Ganem, lan Vickridge, Antoine Seyeux, Philippe Marcus, Diana Serrano, Philippe Goldner, and Alexandre Tallaire

J. Phys. Chem. C, Just Accepted Manuscript • DOI: 10.1021/acs.jpcc.0c04019 • Publication Date (Web): 18 Aug 2020

Downloaded from pubs.acs.org on August 24, 2020

\section{Just Accepted}

"Just Accepted" manuscripts have been peer-reviewed and accepted for publication. They are posted online prior to technical editing, formatting for publication and author proofing. The American Chemical Society provides "Just Accepted" as a service to the research community to expedite the dissemination of scientific material as soon as possible after acceptance. "Just Accepted" manuscripts appear in full in PDF format accompanied by an HTML abstract. "Just Accepted" manuscripts have been fully peer reviewed, but should not be considered the official version of record. They are citable by the Digital Object Identifier (DOI®). "Just Accepted" is an optional service offered to authors. Therefore, the "Just Accepted" Web site may not include all articles that will be published in the journal. After a manuscript is technically edited and formatted, it will be removed from the "Just Accepted" Web site and published as an ASAP article. Note that technical editing may introduce minor changes to the manuscript text and/or graphics which could affect content, and all legal disclaimers and ethical guidelines that apply to the journal pertain. ACS cannot be held responsible for errors or consequences arising from the use of information contained in these "Just Accepted" manuscripts. 


\title{
Harnessing atomic layer deposition and diffusion to spatially localize rare-earth ion emitters
}

\author{
Alban Ferrier ${ }^{1,2}$, Nao Harada ${ }^{1}$, Marion Scarafagio ${ }^{1}$, Emrick Briand ${ }^{3}$, Jean-Jacques Ganem³, Ian \\ Vickridge ${ }^{3}$, Antoine Seyeux ${ }^{1}$, Philippe Marcus ${ }^{1}$, Diana Serrano ${ }^{1}$, Philippe Goldner ${ }^{1}$ and Alexandre \\ Tallaire $^{1}$ \\ ${ }^{1}$ Institut de Recherche de Chimie Paris (IRCP), Université PSL, Chimie ParisTech, CNRS, 75005 \\ Paris, France \\ 2 Sorbonne Université, Faculté des Sciences et Ingénierie, UFR 933, 75005 Paris, France \\ ${ }^{3}$ Sorbonne Universités, Institut des NanoSciences de Paris, INSP, 75005 Paris, France \\ KEYWORDS : Spatial localization of emitters, Atomic Layer Deposition (ALD), Europium diffusion, \\ hole burning spectroscopy, Quantum Technologies \\ *corresponding author: alban.ferrier@chimieparistech.psl.eu
}


ABSTRACT: Control of rare-earth ions doping profiles is a key challenge for several photonics applications and for quantum technologies that require spatially localized emitters. In this work, we propose to use Atomic Layer Deposition (ALD) followed by an annealing post treatment to localize europium emitters close to the surface of an $\mathrm{Y}_{2} \mathrm{O}_{3}$ film or an $\mathrm{Y}_{2} \mathrm{SiO}_{5}$ single crystal by exploiting in-diffusion. Indeed, ALD is a conformal method that can provide in-depth nanometerscale positioning accuracy on a large scale. However, the post thermal annealing required to achieve higher crystalline quality and to activate diffusion, needs to be precisely controlled to maximize our ability to localize ions. In this paper, we evaluate europium ion diffusion in an ALDgrown $\mathrm{Eu}_{2} \mathrm{O}_{3} / \mathrm{Y}_{2} \mathrm{O}_{3} / \mathrm{Si}$ stack using Rutherford Backscattering Spectroscopy (RBS) and Time of Flight Secondary lon Mass Spectrometry (TOF SIMS). We then extend this approach to investigate diffusion from an $\mathrm{Eu}_{2} \mathrm{O}_{3} \mathrm{ALD}$ film into a single crystalline substrate of $\mathrm{Y}_{2} \mathrm{SiO}_{5}(\mathrm{YSO})$, a technologically relevant material system for quantum applications. We determine $\mathrm{Eu}^{3+}$ diffusion coefficients in both cases and show that in the polycrystalline $\mathrm{Y}_{2} \mathrm{O}_{3}$ ALD sub-micron film, diffusion starts at $950^{\circ} \mathrm{C}$ whereas in single crystal YSO it becomes significant, only above $1200^{\circ} \mathrm{C}$. Finally, spectral hole burning of such in-diffused emitters revealed homogeneous lines as narrow as 2 $\mathrm{MHz}$. This study indicates that an appropriate annealing of ALD-grown rare-earth oxide films can 
be harnessed to create localized dopants that preserve their outstanding optical properties, a prerequisite for their integration into photonic and quantum devices.

\section{Introduction}

Lanthanide doped oxide crystalline hosts are well known luminescent platforms for photonic applications. Indeed their unique optical properties have advanced a broad range of applications including lighting, sensors, bio-imaging or more recently Quantum Technologies (QT). ${ }^{1}$ The development of rare-earth (RE) doped films ${ }^{2-8}$ presents several benefits as compared to bulk single crystals. For example, the use of waveguides or multilayer architectures can increase the light matter interaction and thus device operation and sensitivity. In addition, the spatial localization of RE ions closed to the surface is highly desirable for exploiting their coherent properties within a quantum device, in particular for improved coupling to a cavity or to an hybrid structure..$^{9,10,11,12}$ For example in several quantum sensing schemes, the sensitivity scales as the square root of the number of interacting emitters while coupling to the external field to be sensed can be maximized by placing the emitters close to the surface (10s of nanometer). ${ }^{13}$ High emitter concentration closed to the surface is required, whereas emitters inside the bulk will decrease the sensitivity since they are insensitive to the surface perturbation. This closed to surface doping is 
not accessible with classical bulk crystal growth where the dopant is inserted in the melt and is distributed according to the segregation law. Finally, lanthanide dopant concentration profiles along the film might also be of interest for optimized up-conversion or lighting. ${ }^{14}$

Currently, the most common technique for ion localization is ion implantation. Indeed, ion implantation is a powerful approach to precisely localize atoms within a crystalline matrix at controlled depths. ${ }^{15}$ However, implantation induces damage and defects especially when heavy atoms (like lanthanides) are considered. ${ }^{16}$ This defects contribute to increase the spectral broadening of the emitters and reduces the overall performance (e.g. larger homogeneous and inhomogeneous linewidth, lower quantum efficiency). ${ }^{17,18}$ Furthermore the implantation yield is typically less than $50 \%$, indicating that at least half of the implanted ions do not emit photons. This low yield can be very detrimental for QT since decoherence rates are in general related to the coupling with other spins of the matrix (e.g. in particular other implanted yet inactive ions). For instance, to our knowledge, no Spectral Hole Burning (SHB) has been demonstrated on lanthanide-implanted single crystals. However, SHB is a key requirement in QT for the quantum states initialization by allowing spectral tailoring of the inhomogeneous absorption profile by efficient population transfer between ground-state hyperfine levels using optical pumping. ${ }^{1}$ 
Therefore, other strategies that preserve ion properties while allowing high localization efficiency are desirable.

Atomic Layer Deposition (ALD) is highly suited for precisely controlling the composition and nanoscale in-depth positioning of dopants in a thin film. Indeed, the sequential injection of precursors enables a slow layer-by-layer growth mode with a high flexibility. It offers large waferscale process-ability as well as deposition on complex nanostructures. The use of appropriate ligands with large steric hindrance can increase the distance between RE ions in the lateral direction thus improving in-plane positioning as well. 14,19,20 Recently, we demonstrated for ALDgrown $\mathrm{Eu}^{3+}$-doped $\mathrm{Y}_{2} \mathrm{O}_{3}$ thin films using $\mathrm{Y}(\text { tmhd })_{3}$ and ozone as precursors that a high deposition temperature $\left(350^{\circ} \mathrm{C}\right)$ and post treatment annealing above $900^{\circ} \mathrm{C}$ are key parameters for optimizing the luminescent properties. ${ }^{21}$ In fact, by improving the crystalline environment of the ions, inhomogeneous lines of $200 \mathrm{GHz}$ were obtained for the ${ }^{7} \mathrm{~F}_{0} \rightarrow{ }^{5} \mathrm{D}_{0}$ transition of $\mathrm{Eu}^{3+}$ even for nanoscale films (thickness $<100 \mathrm{~nm}$ ) which is a promising first step towards their integration in QTs. One obvious drawback of this approach is related to the fact that at such a high annealing temperature, RE dopants are mobile and can interact at the interface with silicon. Too high annealing temperature is so detrimental since it will lead to modification of the spatial distribution of RE ions, as well as formation of a silicate phase at the interface. ${ }^{21}$ These are detrimental to the 
precise positioning of emitters as well as the control of their environment. Phase mixing indeed affects the frequency range of ions' emission, leads to strong inhomogeneous broadening and increases the dephasing processes rate by disorder mode. ${ }^{22,23}$

Diffusion of lanthanide ions in single crystals or ceramics like $\mathrm{Al}_{2} \mathrm{O}_{3}, \mathrm{Y}_{3} \mathrm{Al}_{5} \mathrm{O}_{12}$ or $\mathrm{YVO}_{4}$ has been reported for a large range of applications including mineralogy, waveguide fabrication or ceramic sintering. ${ }^{24,25,26,27,28}$ For photonics, thermal diffusion of transition metals has been extensively studied to form low cost waveguides in $\mathrm{LiNbO}_{3} \cdot{ }^{29}$ In that case, the transition metal ion acts as a local refractive index modifier leading to passive waveguides. Further works have demonstrated that thermal diffusion is also a useful approach for RE doping in oxide single crystals for laser applications. ${ }^{11}$ However, only scarce data exists on diffusion in nanometer-scale films obtained by ALD or more generally about ions' redistribution during thermal annealing. ${ }^{30}$ Annealing temperature and duration need to be carefully optimized in order to preserve dopant localization or to harness their diffusion, as well as to avoid unwanted phases formation.

In this study, we focus on the diffusion of $\mathrm{Eu}^{3+}$ cations during thermal annealing using Rutherford Backscattering Spectroscopy (RBS) and Time of Flight Secondary lon Mass Spectrometry (TOF SIMS). We first study $\mathrm{Eu}^{3+}$ diffusion in an ALD-grown $\mathrm{Eu}_{2} \mathrm{O}_{3} / \mathrm{Y}_{2} \mathrm{O}_{3} / \mathrm{Si}$ (100) stack in the 600- 
$1000^{\circ} \mathrm{C}$ range (Fig. 1a) from which we determine the diffusion coefficient as well as investigate the reactivity at the interface. This multilayer presents the advantage of being directly grown by ALD on a standard low cost and large area Si wafer but possesses limited crystallinity. We then extend this study to $\mathrm{Eu}^{3+}$ diffusion from an $\mathrm{ALD}$-grown $\mathrm{Eu}_{2} \mathrm{O}_{3}$ layer above a bulk $\mathrm{Y}_{2} \mathrm{SiO}_{5}(\mathrm{YSO})$ single crystalline substrate grown by Czochralski (Fig. 1b) which is the most common host crystal used for RE based QTs. ${ }^{1}$ In this latter case, we demonstrate that diffusion at higher temperatures $\left(1000-1500{ }^{\circ} \mathrm{C}\right)$ can be explored as an alternative to ion implantation in order to create localized RE ions close to the YSO surface, within the first $200 \mathrm{~nm}$. We observe SHB from such in-diffused ions and measure a promising hole linewidth of $4 \mathrm{MHz}$. This indicates that this strategy is suitable to engineer materials that could provide a suitable platform for QTs.

a)

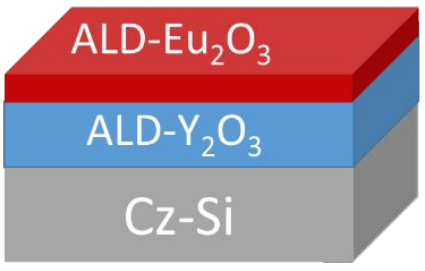

b)

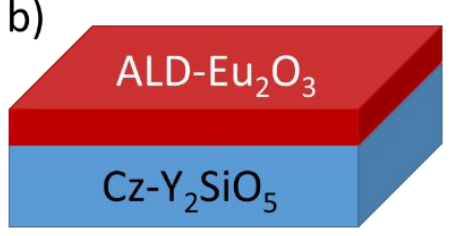

Annealing $600^{\circ} \mathrm{C}-1000^{\circ} \mathrm{C}$

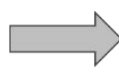

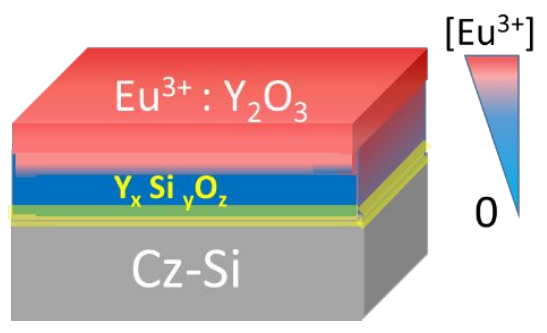

Annealing $1000^{\circ} \mathrm{C}-1500^{\circ} \mathrm{C}$
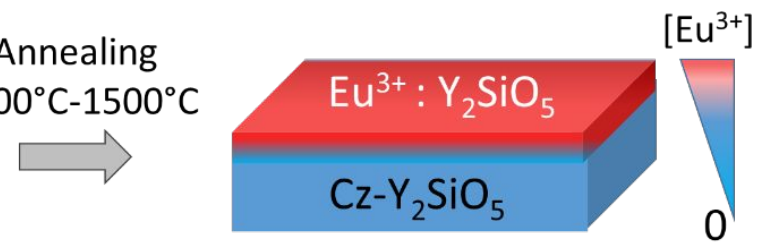


\begin{abstract}
Figure 1: Schematic representation of the two sets of samples investigated. a) Diffusion of Eu ${ }^{3+}$ from a $\mathrm{Eu}_{2} \mathrm{O}_{3}$ layer (typically 15 to $20 \mathrm{~nm}$ thick) on $\mathrm{Y}_{2} \mathrm{O}_{3}(120 \mathrm{~nm}$ thick). The two layers were deposited by $A L D$ on Czochralski silicon (Cz-Si) wafer (100). b) Diffusion of $\mathrm{Eu}^{3+}$ from a $\mathrm{Eu}_{2} \mathrm{O}_{3}$ layer (20 nm thick) deposited on a thick b-oriented single crystalline YSO substrate (010) grown by Czochralski method (Cz) and optically polished.
\end{abstract}

\title{
2. Method
}

$\mathrm{Eu}_{2} \mathrm{O}_{3}$ and $\mathrm{Y}_{2} \mathrm{O}_{3}$ film depositions were carried out by ALD with a Picosun Sunale R200 using conventional $\beta$-diketonate precursors: $\mathrm{Eu}(\mathrm{tmhd})_{3}$ and $\mathrm{Y}(\mathrm{tmhd})_{3}(99.9 \%$ purity from Strem Chemicals). The precursors were held at $160^{\circ} \mathrm{C}$ and delivered using $300 \mathrm{sccm} \mathrm{N}_{2}$ as a carrier gas. Ozone $\left(\mathrm{O}_{3}\right)$ was used as a strong oxidizing agent. The precursors were flown sequentially with $3 \mathrm{~s}$ injection time into the thermalized deposition chamber at $350{ }^{\circ} \mathrm{C}$. The number of cycles was adjusted in order to obtain the desired thickness. More details about the impact of the different deposition parameters and their optimization are discussed in a previous study. ${ }^{21}$ For the $\mathrm{Eu}_{2} \mathrm{O}_{3} / \mathrm{Y}_{2} \mathrm{O}_{3} / \mathrm{Si}$ stack, a first 120 nm-thick $\mathrm{Y}_{2} \mathrm{O}_{3}$ layer was grown on a $\mathrm{Si}(100)$ wafer covered by a native oxide $\left(\mathrm{SiO}_{2}\right)$. Pre-annealing of the cubic $\mathrm{Y}_{2} \mathrm{O}_{3}$ layer at $900{ }^{\circ} \mathrm{C}$ for $2 \mathrm{~h}$ under air was carried out prior to the growth of $15 \mathrm{~nm}$ thick $\mathrm{Eu}_{2} \mathrm{O}_{3}$ (see Fig. 1a). ${ }^{31,32}$ After this pre-annealing yttria films 
remain polycrystalline with strong texturation along (100). ${ }^{21}$ For the second deposition, a slight thickness variation of the $\mathrm{Eu}_{2} \mathrm{O}_{3}$ layer is observed from sample to sample. This thickness variation is possibly due to slightly varying growth conditions and positioning inside the reactor chamber but it does not notably change the diffusion profile.

For the $\mathrm{Eu}_{2} \mathrm{O}_{3} / \mathrm{Y}_{2} \mathrm{SiO}_{5}$ stack, a 20 nm-thick layer was directly deposited by ALD on a specially prepared single crystalline substrate (see Fig. 1b). Monoclinic YSO was grown by Czochralski method $(\mathrm{Cz})$ along the $\mathrm{b}$ direction following the procedure described by Ferrier et al. ${ }^{33,34}$ After crystal orientation by the Laue method, it was cut and optically polished perpendicularly to the $b$ direction.

Film thickness was estimated by white light interferometry in the range 250-1000 nm with an Ocean Optics NanoCalc and an ISE Woollam spectroscopic ellipsometer system. $\mathrm{Eu}_{2} \mathrm{O}_{3}$ and $\mathrm{Y}_{2} \mathrm{O}_{3}$ optical constants have been fitted using a Cauchy model. Thermal annealing was performed in air in the range $600-1500^{\circ} \mathrm{C}$ for $2 \mathrm{~h}$ in order to activate europium diffusion from the top layer into the layer beneath.

RBS and TOF-SIMS bring complementary information and are both explored here to assess $\mathrm{Eu}^{3+}$ diffusion mechanisms. Indeed, RBS is non-destructive and provides quantitative atomic 
composition with a $10 \mathrm{~nm}$ in-depth resolution whereas TOF SIMS is used to determine with high accuracy (less than $1 \mathrm{~nm}$ ) the depth profiling of different elements as already demonstrated for ALD deposited layer on metallic substrates. ${ }^{35-38}$

Ion beam analyses (RBS and NRA) were carried out using the Van de Graaf accelerator of the SAFIR Platform of Sorbonne Université. RBS was performed with $1800 \mathrm{keV}{ }^{4} \mathrm{He}^{+}$beam in a nonchanneling geometry. In RBS, the energy of the backscattered ions depends on both the element with which the ion experienced an elastic collision as well as its depth positioning within the target material. In addition, the area of the peak related to an element is proportional to the atomic density of this element in the material. To determine the concentration profile, a simulation was carried out using the SIMNRA software (more details available on Supplementary Materials). ${ }^{39}$ As we used a silicon substrate, the precise determination of elements lighter than silicon by RBS is complicated. That's why for $\mathrm{Eu}_{2} \mathrm{O}_{3} / \mathrm{Y}_{2} \mathrm{O}_{3} / \mathrm{Si}$, the oxygen areal densities were also determined by nuclear reaction analysis (NRA) using the ${ }^{16} \mathrm{O}(\mathrm{d}, \mathrm{p})^{12} \mathrm{C}$ reaction induced by a deuteron beam of $850 \mathrm{keV}$ and a detection angle of $150^{\circ}$. Indeed, this nuclear reaction is specific to oxygen allowing quantification by a simple integration of the proton peaks on the NRA spectrum (see Figure S1). Then, comparison of those integrated values with two standards of $\mathrm{Ta}_{2} \mathrm{O}_{5}$ allowed precise 
determination of the oxygen composition of the thin film. Good agreement was obtained between the $\mathrm{O}$ content extracted from RBS and NRA studies with typical variation of about $2 \%$.

The in-depth concentration profiles were also studied using a dual-beam TOF-SIMS V spectrometer (ION-TOF GmbH, Muenster, Germany). Indeed, we measured the concentration depth profile of the yttrium and erbium ions at a sufficiently low primary ion dose density to keep static conditions. Charge compensation was performed by using an electron flood gun. The spectrometer was operated at a pressure of $10^{-9}$ mbar. A pulsed $25 \mathrm{kV} \mathrm{Bi}^{+}$primary ion beam delivering $1 \mathrm{pA}$ over a $100 \times 100 \mu \mathrm{m}^{2}$ area is used to extract the chemical species from the surface. The masses of the removed chemical species are determined by time-of-flight mass

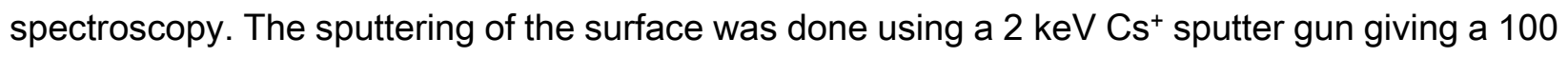
$\mathrm{nA}$ target current over a $300 \times 300 \mu \mathrm{m}^{2}$ area. The interlacing between $\mathrm{Bi}^{+}$and $\mathrm{Cs}^{+}$guns allows to record TOF-SIMS depth profiles. Analysis was centered inside the sputtered crater to avoid edge effects. Data acquisition and post-processing were carried out using Surface Lab 6.7 software. The sputter profiles were converted into depth by measuring the crater's depth with a surface profiler (Dektak 150, Veeco), assuming a constant sputtering rate. The main uncertainty of this data results from the limited accuracy of the depth scaling. TOF-SIMS is destructive but is well adapted to determine dopant concentration profiles being done with accuracy better than $1 \mathrm{~nm}$. 


\begin{abstract}
Furthermore, TOF-SIMS requires precisely calibrated standards and is function of the analyzed
matrix for quantitative assessment since the ionization yield of each element is generally different,

Eu and $\mathrm{Y}$ contributions were assessed by following $\mathrm{EuO}_{2}^{-}$and $\mathrm{YO}^{-}$sputtered ions signals.

Contribution from other elements ( $\mathrm{SiO}^{-}, \mathrm{C}$ and $\mathrm{Si}$ ) were also analyzed but will not be discussed in

detail in this paper. In particular, the precise determination of the top layer's thickness was difficult

due to the roughness induced by the annealing post treatment.
\end{abstract}

Finally, SHB experiments were performed with a homemade low temperature microscope using

a high numerical aperture lens on a nano-positionner (See Supplementary Materials for more

details and Figure S4). Briefly, samples were introduced into a He bath cryostat (Janis SVT-200.

The temperature was monitored directly on the sample-holder by a Si diode (Lakeshore DT-670).

A continuous wave (CW) dye laser (Sirah Matisse DS) with $300 \mathrm{kHz}$ linewidth provided the optical

excitation around $580 \mathrm{~nm}$. Pulsed sequences required for SHB measurements were created by

modulating the $\mathrm{CW}$ laser with one acousto-optic modulator driven by an arbitrary waveform

generator (Agilent N8242A). The red luminescence was filtered using band-pass and interferential

filters and sent to a high sensitivity photomultiplier (PMT R10699 Thorlabs).

\title{
3. Results and discussion
}




\section{1. $\mathrm{Eu}^{3+}$ diffusion in an $\mathrm{ALD}-\mathrm{grown} \mathrm{Eu}_{2} \mathrm{O}_{3} / \mathrm{Y}_{2} \mathrm{O}_{3} / \mathrm{Si}(100)$ stack}

We first focus on reactions occurring at the substrate/layer interface of the ALD-grown polycrystalline $\mathrm{Eu}_{2} \mathrm{O}_{3} / \mathrm{Y}_{2} \mathrm{O}_{3} / \mathrm{Si}(100)$ stack during thermal annealing. Typical RBS spectra for 2 different annealing temperatures are presented in Fig. 2. The contribution from silicon, oxygen, yttrium and europium are clearly visible. No additional elements appear on the RBS spectrum indicating no obvious contamination with elements heavier than silicon. Carbon was found to be below the detection limit of RBS. However, the detection of elements lighter than the substrate is always challenging in RBS since their signals are superimposed to that from the substrate. NRA was thus used to quantify oxygen and check the carbon content (Figure S1). The evolution of the composition assessed from the integration of the RBS and NRA signals is illustrated in Table 1. For the as-grown film, the RE to oxygen ratio is close to the expected stoichiometric value (0.4) but with a slight excess of oxygen. This excess is likely due to the diffusion of oxygen inside the sesquioxide structure during the annealing under air. Another source of oxygen overstoichiometry is the formation of silicate parasitic phases at the silicon interface during the preannealing of the $\mathrm{Y}_{2} \mathrm{O}_{3} / \mathrm{Si}$ template prior to $\mathrm{Eu}_{2} \mathrm{O}_{3}$ deposition. Using SIMNRA software fitting, we evaluate a $\mathrm{SiO}_{2}$ layer of $30 \mathrm{~nm}$ for a $900^{\circ} \mathrm{C}$ annealing post treatment, in reasonably good agreement with the $22 \mathrm{~nm}$ determined by spectroscopic ellipsometry (Figure S2). When the 
annealing temperature of the multilayer is increased above $900{ }^{\circ} \mathrm{C}$, interfacial reactions take place again leading to a further increase of the oxygen over-stoichiometry (see Table 1 and Figure S2). An increase of the $\mathrm{SiO}_{2}$ interlayer's thickness was evidenced by spectroscopic ellipsometry measurements (Figure S2) and is reported in the last column of Table 1. The silicon oxidation is also clearly evidenced on the RBS spectra of Fig. 2c where a shoulder at the silicon front edge appears, indicating the formation of an oxide interlayer. Annealing at temperatures higher than $100{ }^{\circ} \mathrm{C}$ could not be carried out since the reaction between the layer and the substrate leads to a depletion of the $120 \mathrm{~nm}$-thick yttria layer into orthosilicate and/or pyrosilicate phases, which are not desirable. ${ }^{21,40}$ This indeed sets the upper temperature limit for annealing such multilayers if one wants to keep a constant crystalline environment for the ions. 

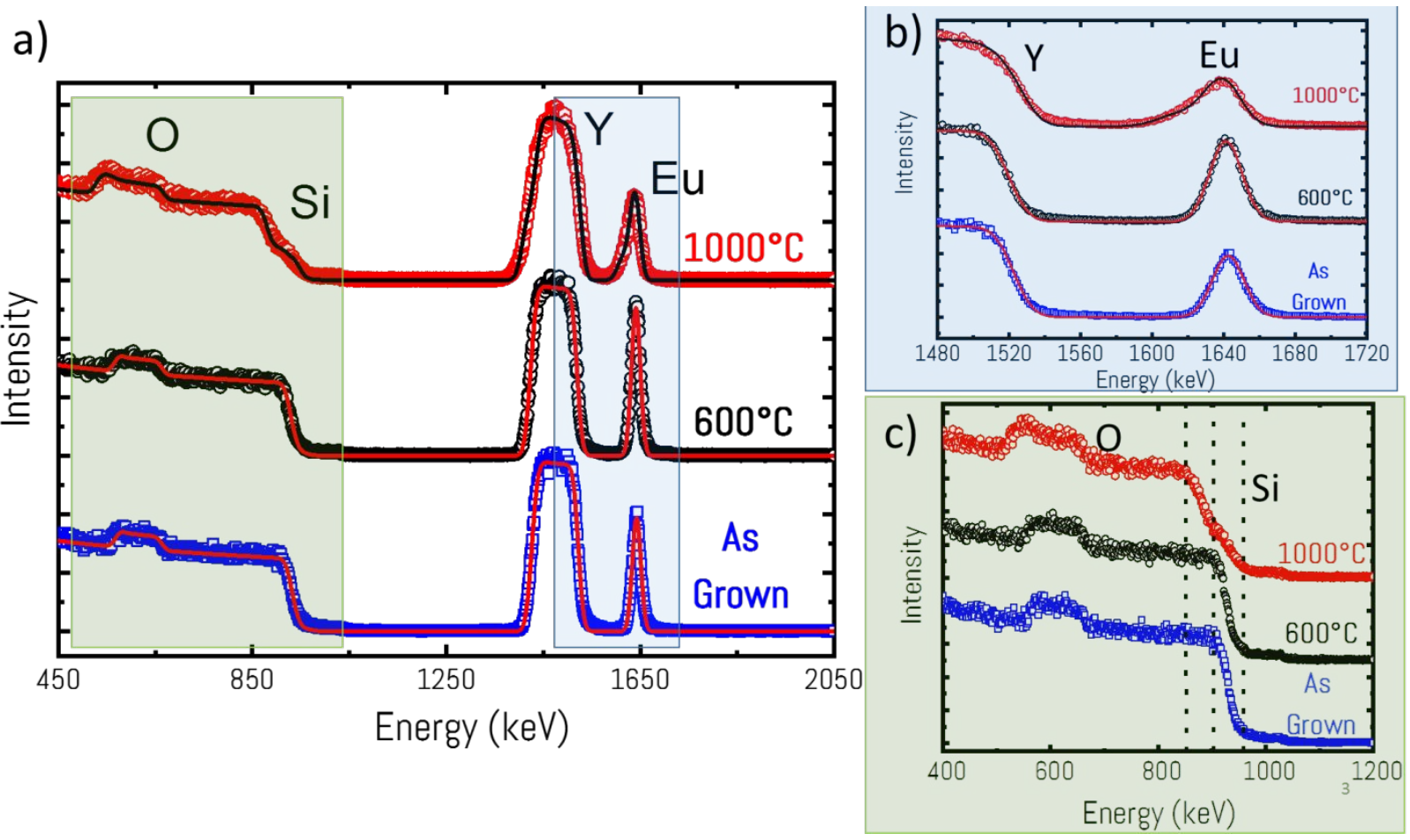

Figure 2 (a) RBS spectra of a $\mathrm{Eu}_{2} \mathrm{O}_{3} / \mathrm{Y}_{2} \mathrm{O}_{3} /$ Si stack either as-grown or annealed at 600 or $1000{ }^{\circ} \mathrm{C}$ for 2 hours. (b) Zoom into the region highlighted in blue. Experimental data are dots points whereas SIMNRA simulation is presented with solid lines. (c) Zoom into the region highlighted in green. Data are vertically translated for better clarity.

Table 1 : RBS and NRA quantification data. The $\mathrm{SiO}_{2}$ thickness estimated from ellipsometry is also presented. The oxygen content used for the determination of the integrated stoichiometry 
was determined by subtracting the oxygen content in the parasitic interfacial layers determined by the RBS simulation to the total content of oxygen. A good agreement between the thickness of the $\mathrm{SiO}_{2}$ layer determined by the RBS simulation and ellipsometry is observed (see also Figure S2). The expected stoichiometry is 0.4. * Note that for the as-grown layer, pre-annealing of the $\mathrm{Y}_{2} \mathrm{O}_{3}$ layer at $900{ }^{\circ} \mathrm{C}$ for $2 \mathrm{~h}$ was carried out prior to $\mathrm{Eu}_{2} \mathrm{O}_{3}$ deposition.

\begin{tabular}{|c|c|c|c|c|c|}
\hline Samples & $\begin{array}{c}\mathrm{Y} \\
\mathrm{RBS} \\
\left(\begin{array}{c}10^{15} \mathrm{at} / \mathrm{cm}^{2} \\
)\end{array}\right.\end{array}$ & $\begin{array}{c}\mathrm{Eu} \\
\mathrm{RBS} \\
\left(10^{15} \mathrm{at} / \mathrm{cm}^{2}\right. \\
)\end{array}$ & $\begin{array}{c}\text { O } \\
\text { NRA } \\
\left(10^{15} \mathrm{at} / \mathrm{cm}^{2}\right. \\
)\end{array}$ & $\begin{array}{l}\text { Stoichiometry } \\
\qquad \int(\mathrm{Y}+\mathrm{Eu}) / \int \\
(\mathrm{Y}+\mathrm{Eu}+\mathrm{O} *\end{array}$ & $\begin{array}{l}\quad \mathrm{SiO}_{2} \\
\text { thickness } \\
\text { ellipsometry } \\
\qquad(\mathrm{nm})\end{array}$ \\
\hline As grown* & 301 & 20 & 670 & 0.35 & 22 \\
\hline${ }_{h} 600{ }^{\circ} \mathrm{C} / 2$ & 301 & 24 & 690 & 0.35 & 24 \\
\hline${ }_{h} 800{ }^{\circ} \mathrm{C} / 2$ & 301 & 15 & 702 & 0.35 & 28 \\
\hline $900{ }^{\circ} \mathrm{C} / 2$ & 296 & 14 & 836 & 0.35 & 52 \\
\hline $\begin{array}{l}950{ }^{\circ} \mathrm{C} / 2 \\
\mathrm{~h}\end{array}$ & 298 & 24 & 1071 & 0.34 & 107 \\
\hline $1000^{\circ} \mathrm{C} / 2$ & 307 & 21 & 1081 & 0.34 & 118 \\
\hline
\end{tabular}


We then evaluate europium diffusion into the yttrium oxide layer beneath. yttrium and europium have the same valence state $(3+)$ and similar ionic radii (4\% difference) that lead to possible inter-diffusion when heated. ${ }^{41}$ RBS spectra of Figure $2 a$ were fitted using the SIMNRA software. The staircase-shape $\mathrm{Eu}^{3+}$ depth profile that was used to get a good fit is presented in Figure 3 for different annealing temperatures (see also Figure S3). We observe that the $\mathrm{Eu}^{3+}$ distribution starts to change only for temperatures above $900^{\circ} \mathrm{C}$ with significant $\mathrm{Eu}^{3+}$ and $\mathrm{Y}^{3+}$ inter-diffusion at $950^{\circ} \mathrm{C}$. This large temperature of inter-diffusion is due to the refractory character of $\mathrm{Y}_{2} \mathrm{O}_{3}$ and $\mathrm{Eu}_{2} \mathrm{O}_{3}$ with melting temperatures of about $2400^{\circ} \mathrm{C}$. We note though that the considered films are polycrystalline and that higher diffusion is expected than in single crystal materials due to the presence of grain boundaries. For the $1000^{\circ} \mathrm{C}$ case, the RBS composition indicates that the europium concentration starts to be depleted at the surface. The concentration distribution after a diffusion anneal is described by the thin film diffusion solution. ${ }^{42}$ Therefore, we fit the curve with the diffusion Gaussian function such as :42

$$
C(z, t)=A * \exp ^{-\left(\frac{z^{2}}{4 D t}\right)} \text { with } A=\frac{\tau C_{0}}{\sqrt{\pi D t}} \text { (eq. 1.) }
$$

where $\tau$ is the initial film thickness of $\mathrm{Eu}_{2} \mathrm{O}_{3}, \mathrm{C}_{0}$ is the maximum solid solubility of $\mathrm{Eu}^{3+}$ in $\mathrm{Y}_{2} \mathrm{O}_{3}$. Using this equation, we were able to simulate the staircase profile considered in our RBS fit (see 
purple and red square curves of Fig. 3) and to extract a diffusion coefficient of $4.5 \times 10^{-21}$ and $2 \times 10^{-}$ $20 \mathrm{~m}^{2} \cdot \mathrm{s}^{-1}$ at $950^{\circ} \mathrm{C}$ and $1000{ }^{\circ} \mathrm{C}$ respectively. However, a relatively large uncertainty is expected due mainly to the low accuracy in depth resolution of RBS and the surface roughness. In order to obtain more precisely the diffusion coefficient, TOF-SIMS analyses were performed.

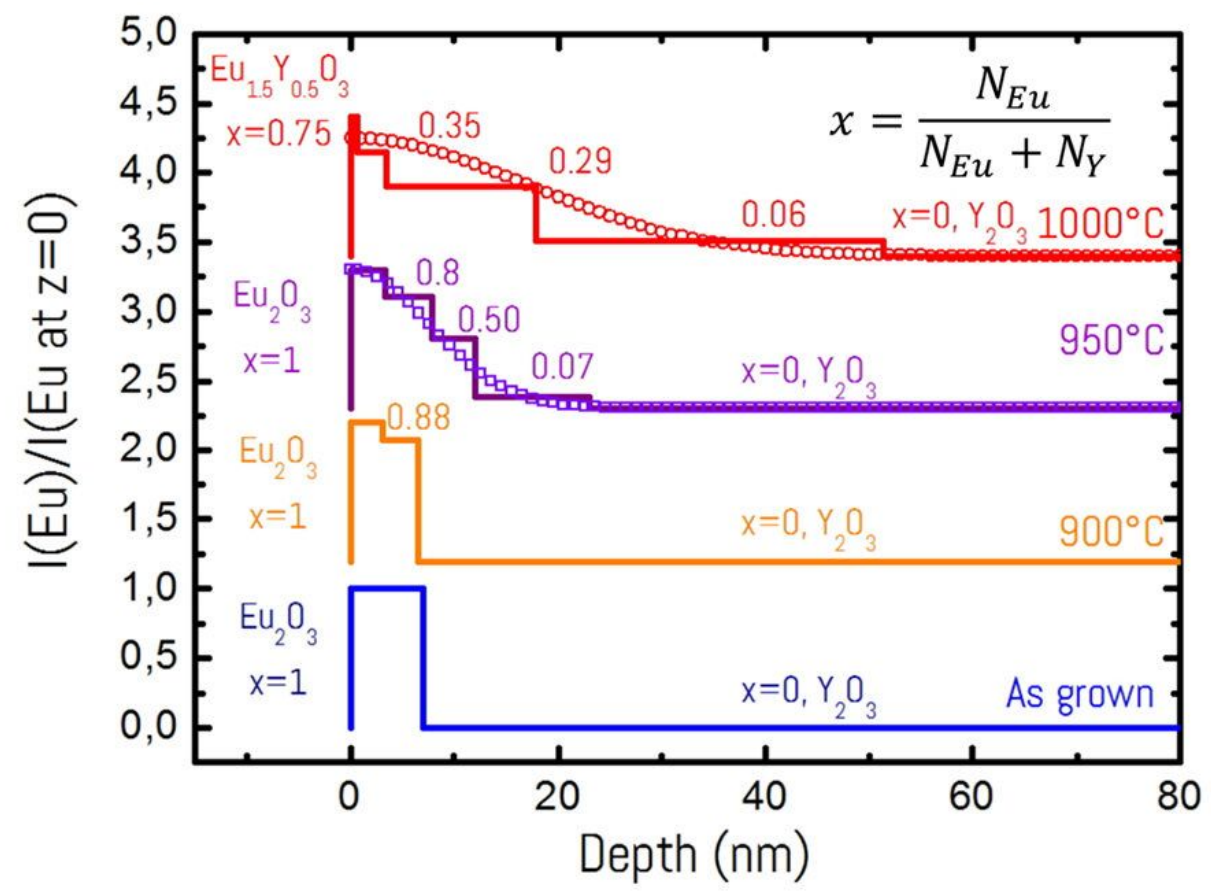

Figure 3. Comparison of diffusion depth profiles of Eu in the $\mathrm{Eu}_{2} \mathrm{O}_{3} / \mathrm{Y}_{2} \mathrm{O}_{3} /$ Si stack for different annealing temperatures. The solid lines correspond to the staircase Eu distribution used in the SIMNRA simulation of the RBS spectra. For the two highest temperatures, we simulate the diffusion with the Gaussian function distribution using Eq. 1 (dots and square points). The depth (z) has been determined assuming a density of $5.3 \mathrm{~g} \mathrm{~cm}^{3}$ and $7.02 \mathrm{~g} \mathrm{~cm}^{3}$ for $\mathrm{Y}_{2} \mathrm{O}_{3}$ and $\mathrm{Eu}_{2} \mathrm{O}_{3}$ 
respectively. The cationic composition has been indicated for each sublayer using the ratio $x$ where $x=N_{E u} /\left(N_{E u}+N_{Y}\right)$. The data have been vertically shifted and normalized to the Eu content value at the surface $(z=0)$ for clarity.

The main advantage of TOF-SIMS is the sub-nm depth resolution in comparison to the few $\mathrm{nm}$ resolution of RBS. The depth profiles of $\mathrm{Eu}, \mathrm{Y}, \mathrm{Si}, \mathrm{C}$ and $\mathrm{O}$ in the as-grown thin layers are presented in Fig. 4. Carbon contamination is clearly detected which is expected to originate mainly from the surface and possibly from the long carbon chains of the ALD precursors. The TOF SIMS spectra demonstrated a chemically stable and well-defined interface between $\mathrm{Eu}_{2} \mathrm{O}_{3}, \mathrm{Y}_{2} \mathrm{O}_{3}$ and $\mathrm{Si}$ for the as-grown layers from the abrupt changes and little overlapping of the signals. Eu ions appear to be located within the top $15 \mathrm{~nm}$. When the sample is annealed at high temperature, the Eu signal spread out over up to $60 \mathrm{~nm}$ (Fig. 4b and 4c) confirming diffusion. A good agreement is observed between the Eu staircases deduced from RBS with the Eu profile element measured by TOF-SIMS (Figure S3). Using the same equation as before (Eq. 1), we were able to estimate the diffusion coefficients to $4 \times 10^{-21}$ and $1.8 \times 10^{-20} \mathrm{~m}^{2} \cdot \mathrm{s}^{-1}$ at $950^{\circ} \mathrm{C}$ and $1000{ }^{\circ} \mathrm{C}$ respectively. The diffusion coefficient plotted in Fig. 5 together with those estimated by RBS indeed agree fairly well. 


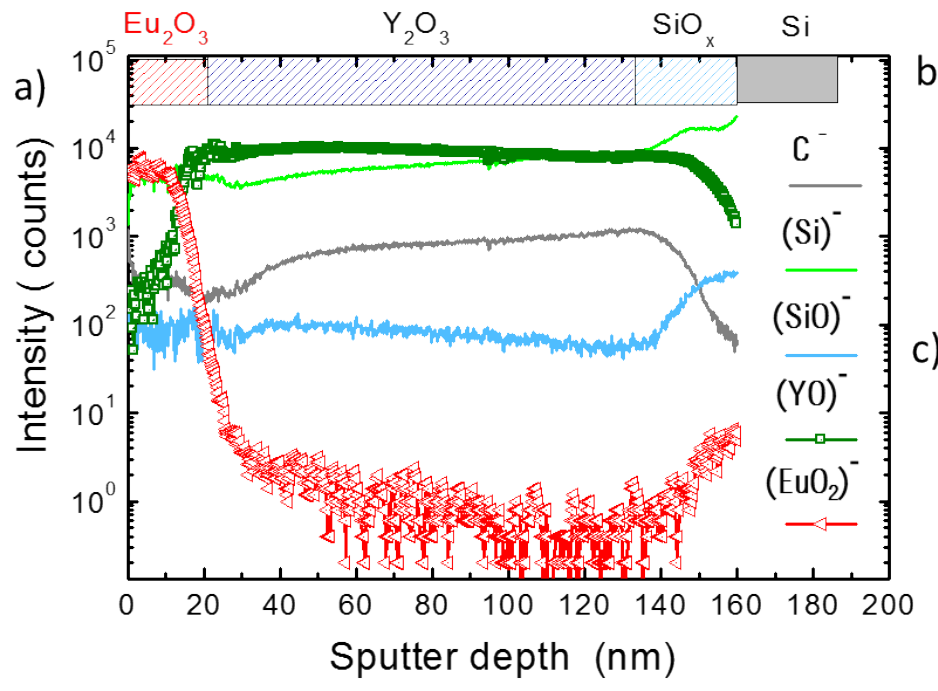

b)

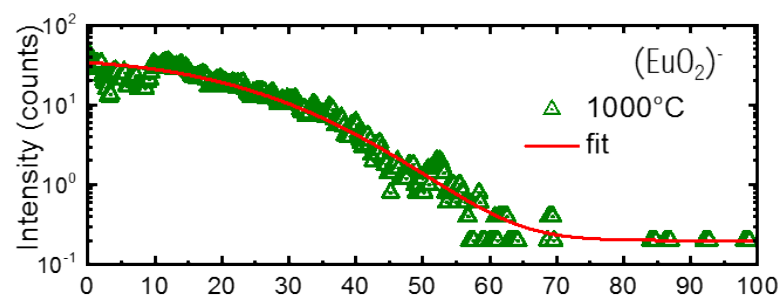

c)

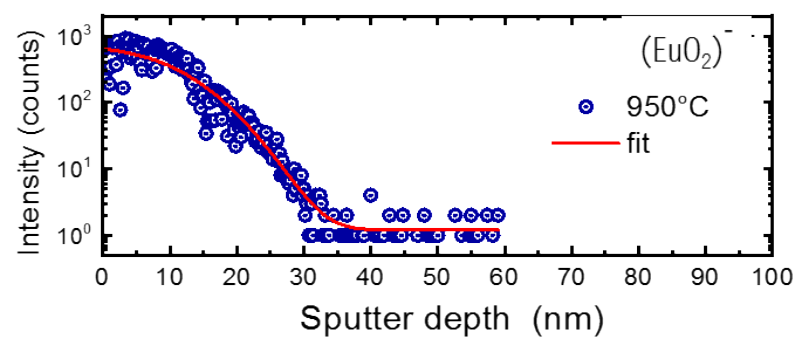

Figure. 4: TOF-SIMS analysis of a thin $\mathrm{Eu}_{2} \mathrm{O}_{3} / \mathrm{Y}_{2} \mathrm{O}_{3} /$ Si stack. (a) Before annealing from which the different layers can be clearly identified. (b) and (c) Profiles of the Eu element for annealing at $1000^{\circ} \mathrm{C}$ and $950^{\circ} \mathrm{C}$ for $2 \mathrm{~h}$ respectively. Dots are experimental results while solid lines are modelling using diffusion equations (1). 


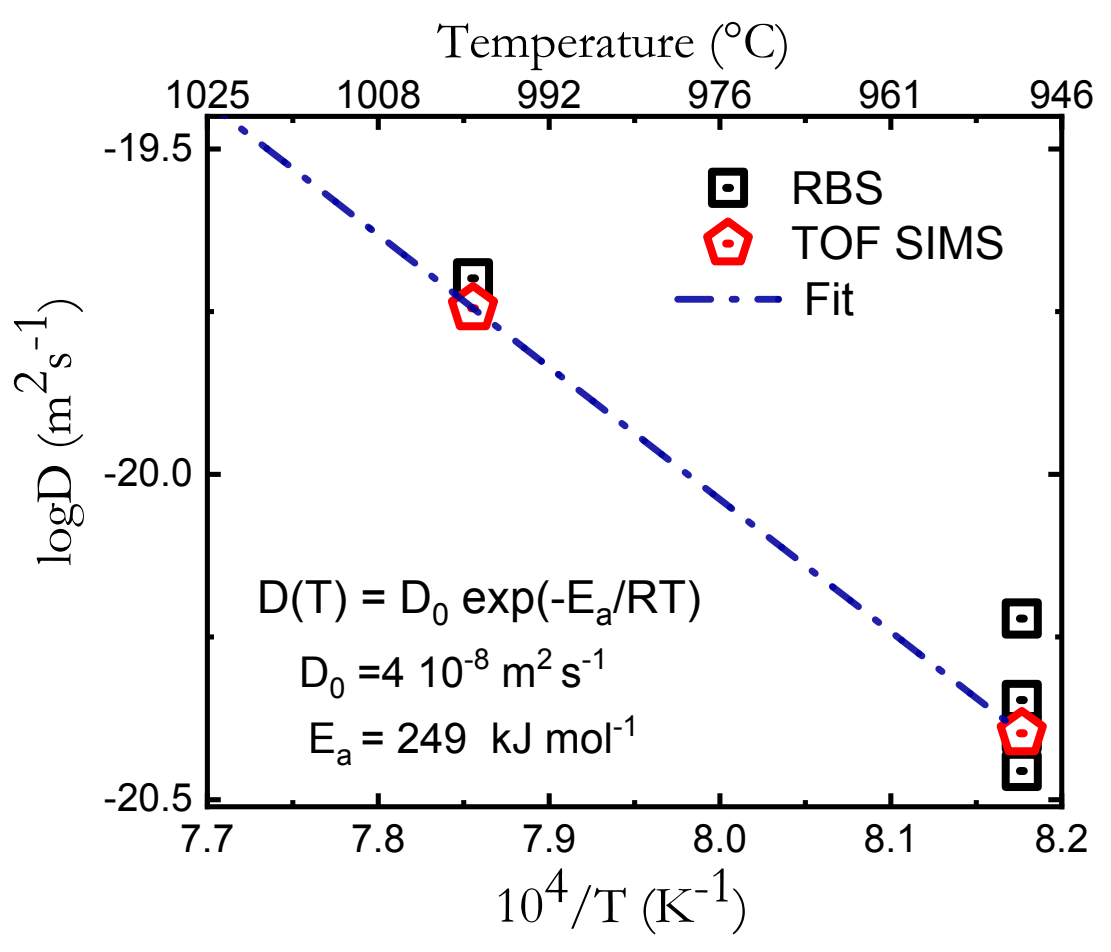

Figure 5: Europium's diffusion coefficient as a function of the reciprocal of the absolute annealing temperature (Arrhenius plot) from TOF SIMS and RBS. Symbols are experimental points and solid line is the fit using an Arrhenius law. For $950^{\circ} \mathrm{C}$ annealing post-treatment, measurements have been performed for different durations. Arrhenius parameters extracted from the fit are presented in the figure.

From those measurements, we deduced the activation energy according to the well-known Arrhenius equation:

$$
D(T)=D_{0} e^{-\left(\frac{E_{a}}{R T}\right)} \quad \text { (eq. 2) }
$$


where $D_{0}$ is a prefactor, $E_{a}$ is the activation energy and T the temperature. The activation energy is about $249 \mathrm{~kJ} \mathrm{~mol}^{-1}$ for both RBS and SIMS data. As only two temperatures have been considered, this calculation has limited validity. Nevertheless, those $\mathrm{E}_{\mathrm{a}}$ values are close to those of self-diffusion reported for yttrium in the literature that are comprised between 246 and $320 \mathrm{~kJ}$

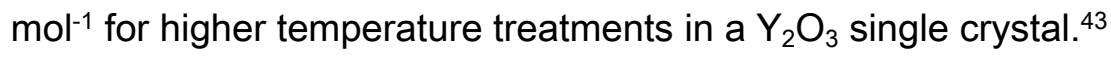

In summary, $\mathrm{Eu}^{3+}$-diffusion into a polycrystalline ALD film of $\mathrm{Y}_{2} \mathrm{O}_{3}$ occurs significantly only for temperatures above $900^{\circ} \mathrm{C}$, while the formation of an interfacial oxide phase on silicon remains limited in the $900^{\circ} \mathrm{C}-1000^{\circ} \mathrm{C}$ annealing temperature range. This indicates that postdeposition thermal treatment at moderate temperatures can be harnessed to improve the luminescent properties of ALD-grown films without affecting the in-depth spatial localization of RE ions. This approach opens the way to the fabrication of complex planar multilayer structures in order to increase the photoluminescence or to manage energy transfer using the same strategies than that used with multi core-shell doping in up-conversion nanocrystals. ${ }^{44-46}$ We then extended this approach to the context of QTs where localized emitters closed to the surface are especially desirable. For that purpose, we probed $\mathrm{Eu}^{3+}$ ion diffusion into quantum-grade quality $\mathrm{Y}_{2} \mathrm{SiO}_{5}$ single crystals since YSO has already been used in some of the most advanced demonstrations in QTs. ${ }^{47-49}$ 


\section{2. $\mathrm{Eu}^{3+}$ diffusion in $\mathrm{Y}_{2} \mathrm{SiO}_{5}$ single crystals}

A $20 \mathrm{~nm}$-thick $\mathrm{Eu}_{2} \mathrm{O}_{3}$ ALD film was deposited on undoped $\mathrm{Y}_{2} \mathrm{SiO}_{5}$ single crystal substrates that were cut perpendicular to the $b$ axis and optically polished (Fig. 1b). Different annealing temperatures and duration times, as shown in Table 2, were used to activate diffusion from the $\mathrm{Eu}^{3+}$ containing layer into the crystal. Analysis was carried out by a combination of TOF-SIMS and RBS. In the RBS spectra of Figure 6, the calculated $\mathrm{Eu}^{3+}$ atomic density from the integration of the peak appears constant and independent of the thermal post-treatment (see Table S1) indicating that $\mathrm{Eu}^{3+}$ loss does not occur. However, with annealing at temperatures above $1200{ }^{\circ} \mathrm{C}$, the RBS $\mathrm{Eu}^{3+}$-related peak became asymmetric on the low energy side (i.e. at greater depths) confirming $\mathrm{Eu}^{3+}$ diffusion into the $\mathrm{YSO}$ substrate. Moreover, a $\mathrm{Y}$ out-diffusion into the film is also observed since the Y-related contribution of the substrate becomes modified on the high-energy side (i.e. indicating $\mathrm{Y}$ atoms are located closer to the surface). Apart from this, no modification of the substrate was observed even for the highest annealing temperatures. This is a clear advantage of this approach as compared to the previously considered thin ALD multilayer stack where the formation of an interlayer oxide with the substrate limits the maximum annealing temperature. To evaluate diffusion from the film, we performed simulation of the RBS spectra with SIMNRA multilayer. However due to the low depth resolution and the overlapping of the 2 main 
peaks ( $\mathrm{Y}$ and $\mathrm{Eu}$ ) a precise value of the diffusion coefficient could not be extracted. We thus turned to TOF-SIMS that can provide more accurate depth analysis.

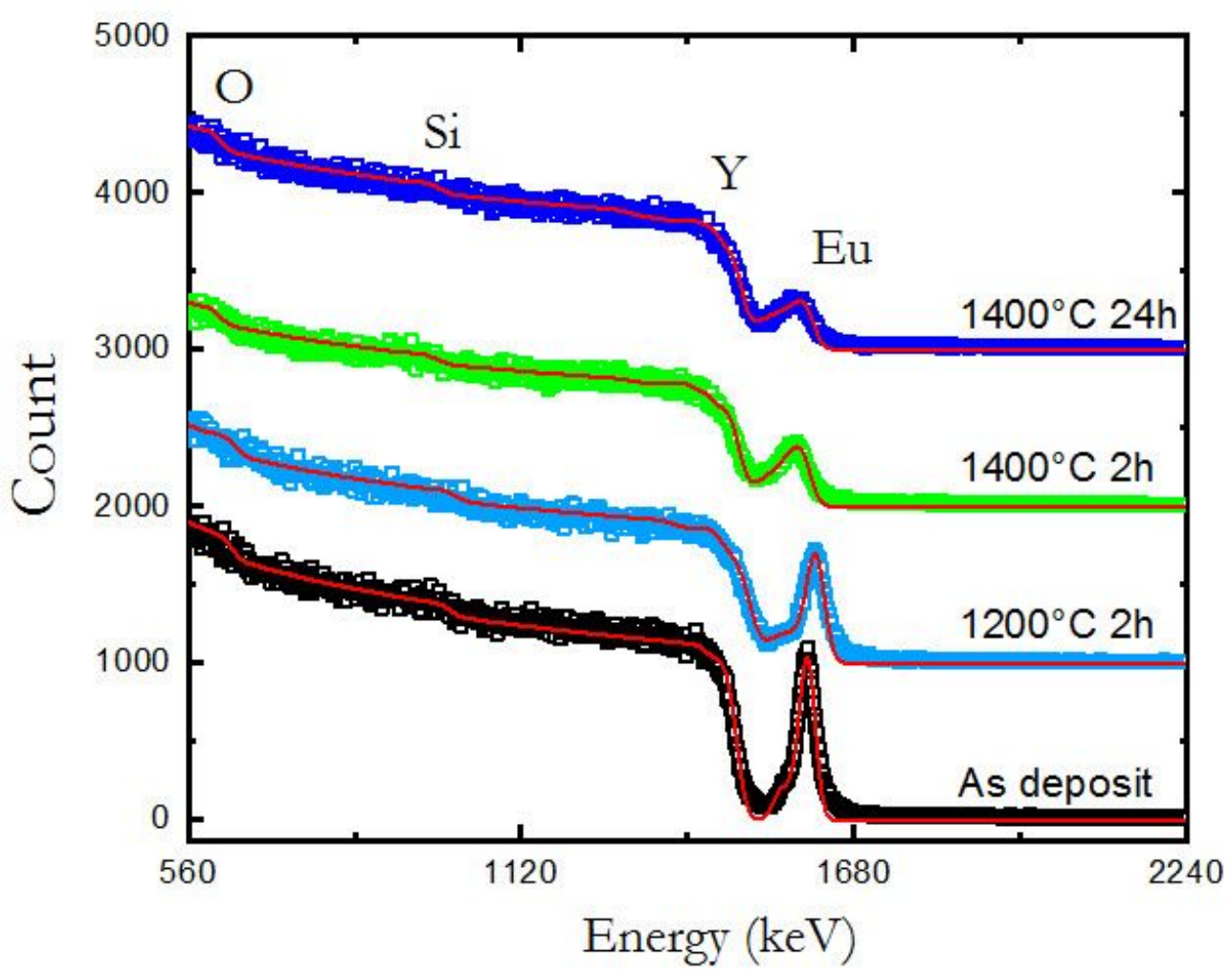

Figure 6: RBS spectra showing europium diffusion from a $\mathrm{Eu}_{2} \mathrm{O}_{3} \mathrm{ALD}$ layer into a $\mathrm{Y}_{2} \mathrm{SiO}_{5}$ single crystal substrate as a function of the annealing treatment. Square points are experimental data whereas solid lines represent simulation with the SIMNRA software. For all curves, a similar content of Europium has been deduced from the simulation (see Table S1). The curves have been translated vertically for better clarity. 
Typical experimental curves relative to Eu and $\mathrm{Y}$ contributions in TOF-SIMS are presented in Fig.

7. For the as-grown ALD film, an abrupt decrease of the $\mathrm{EuO}_{2}{ }^{-}$signal indicates a well-defined interface between the $20 \mathrm{~nm}$-thick $\mathrm{Eu}_{2} \mathrm{O}_{3}$ film and the $\mathrm{YSO}$ substrate. When the annealing temperature is increased up to $1400{ }^{\circ} \mathrm{C}$, diffusion of Eu ions into YSO occurs as shown from the spreading of the $\mathrm{EuO}_{2}{ }^{-}$signal (Fig. 7a). Similarly, diffusion of yttrium ions from the substrate into the ALD layer is also visible from the shape of the YO- signal in Fig. 7b. When looking in more details at the Eu-related contribution, one can note that for short annealing, the semi-logarithmic plot indicates a two-component concentration profile of Eu inside YSO, which is far less observed for the long $1400^{\circ} \mathrm{C}$ annealing (see Fig. $8 \mathrm{a}$ and $8 \mathrm{~b}$ ). In the latter case, $\mathrm{Eu}^{3+}$ distribution can be well fitted by a Gaussian distribution (Equation 1). Two-component diffusion profiles have already been observed in polycrystalline materials such as ceramics and have been classified by Harrison in three different kinetics regimes called $A, B$ and $C .{ }^{42,50}$ These different regimes exist due to the presence of several diffusion paths with different coefficients. Indeed, the diffusion coefficient inside the bulk material is significantly smaller than at the grain boundary for polycrystalline materials or for diffusion at dislocations in single crystals. For the A regime the bulk diffusion and the faster diffusion process are averaged and only an effective diffusion $D_{\text {eff }}$ coefficient is observed. This A kinetics is observed for high temperature or longer annealing times and a 
Gaussian diffusion profile is expected for depleted source. For B regime, the diffusion profile presents two different slopes. The first slope of the profile corresponds to the effective diffusion $D_{\text {eff }}$ across the bulk materials whereas the second part of the profile, i.e. the curved tail, is characteristic of the diffusion along the fast path (grain boundaries, dislocation etc...). ${ }^{42}$ Indeed, thermal diffusion of ions in single crystals has revealed that large tails in the concentration profile can be created as a consequence of the existence of dislocations that act as "short circuits" for the thermally diffused ions, leading to unusual large penetration. ${ }^{51}$ The $\mathrm{C}$ kinetics corresponds to condition where the bulk diffusion is extremely low and is not in agreement with our experimental conditions. According to Harrison model only one diffusion is expected in single crystal but the B regime has already been observed in several materials. ${ }^{51,52}$ Possible explanations are the existence of dislocations or of large anisotropy cationic diffusion with the direction as already observed for other oxide. ${ }^{25,52}$ The latter effect should be important in our crystal since YSO is monoclinic. Indeed, for YSO the diffusion parameter is described with a second rank symmetric tensor with 4 independent parameters. More studies are required in order to fully characterize this process.

The diffusion coefficients extracted from the Gaussian distribution for different temperatures or annealing durations are presented in Table 2. As expected, an increase of the diffusion 
coefficients is observed with the annealing temperature. Indeed, the effective diffusion coefficient is estimated to $2 \times 10^{-21}$ and $5 \times 10^{-20} \mathrm{~m}^{2} \cdot \mathrm{s}^{-1}$ at 1200 and $1400{ }^{\circ} \mathrm{C}$ respectively. The obtained diffusion coefficients of $\mathrm{Eu}^{3+}$ in $\mathrm{YSO}$ are small and of the same order of magnitude than lanthanides in other refractory oxides (such as $\mathrm{YVO}_{4}$ and $\mathrm{YAG}$ ) that are shown for comparison in Table 2. Eu diffusivity in YSO appears similar to that observed for other lanthanides. The diffusion of different trivalent lanthanides can be compared since lanthanide diffusion exhibits only a weak dependence on ionic radius for various minerals, both silicates and non-silicates. ${ }^{53}$

Finally, the calculated diffusion coefficients were plotted in Fig. 9 as a function of temperature. The activation energy of $\mathrm{Eu}^{3+}$ in $\mathrm{YSO}$ was estimated to $260 \mathrm{~kJ}^{\mathrm{mol}}{ }^{-1}$. This value is in the characteristic range for lanthanides in oxide single crystals. ${ }^{27}$

a)

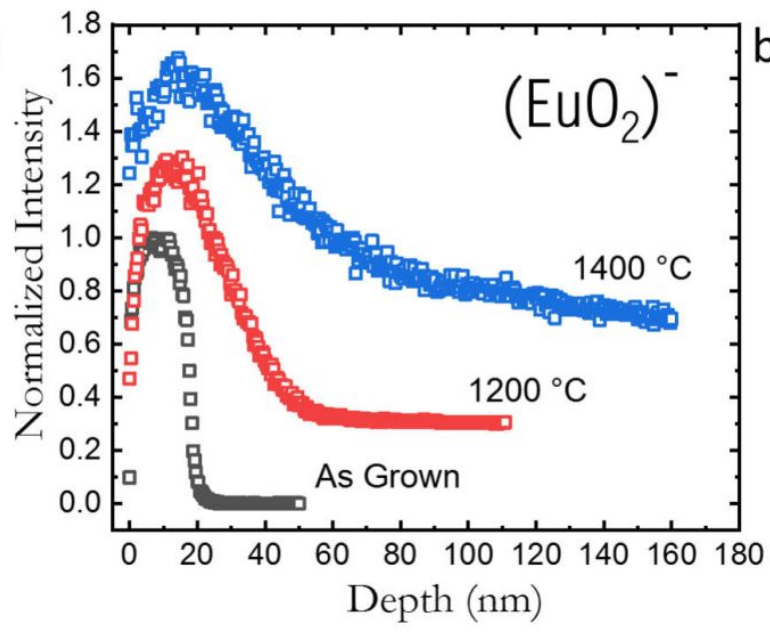

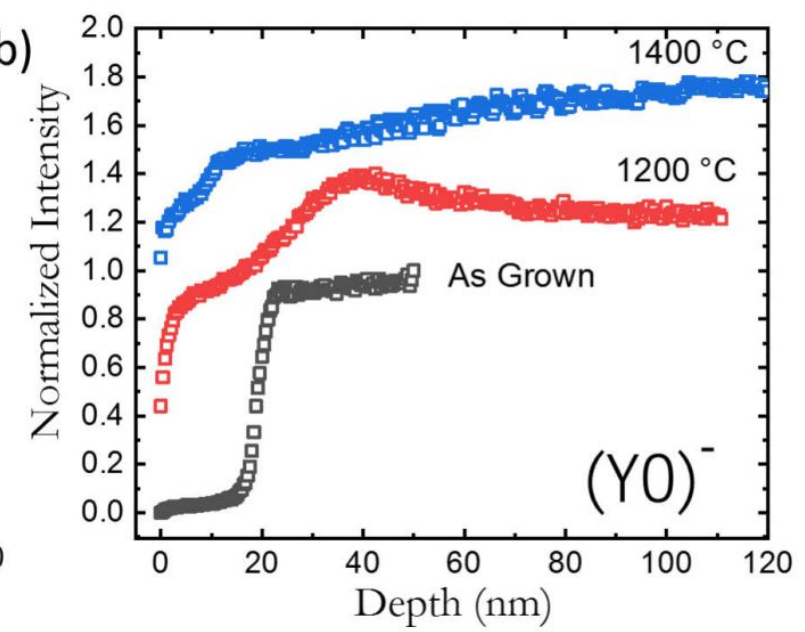


Figure 7: TOF-SIMS analysis of a thin $\mathrm{ALD}$-grown $\mathrm{Eu}_{2} \mathrm{O}_{3}$ thin film on $\mathrm{Y}_{2} \mathrm{SiO}_{5}$ showing the Eu and $Y$ related signals at different annealing temperatures. Annealing duration was $2 h$. The curves have been normalized to their maximum and vertically translated for better clarity.

a)
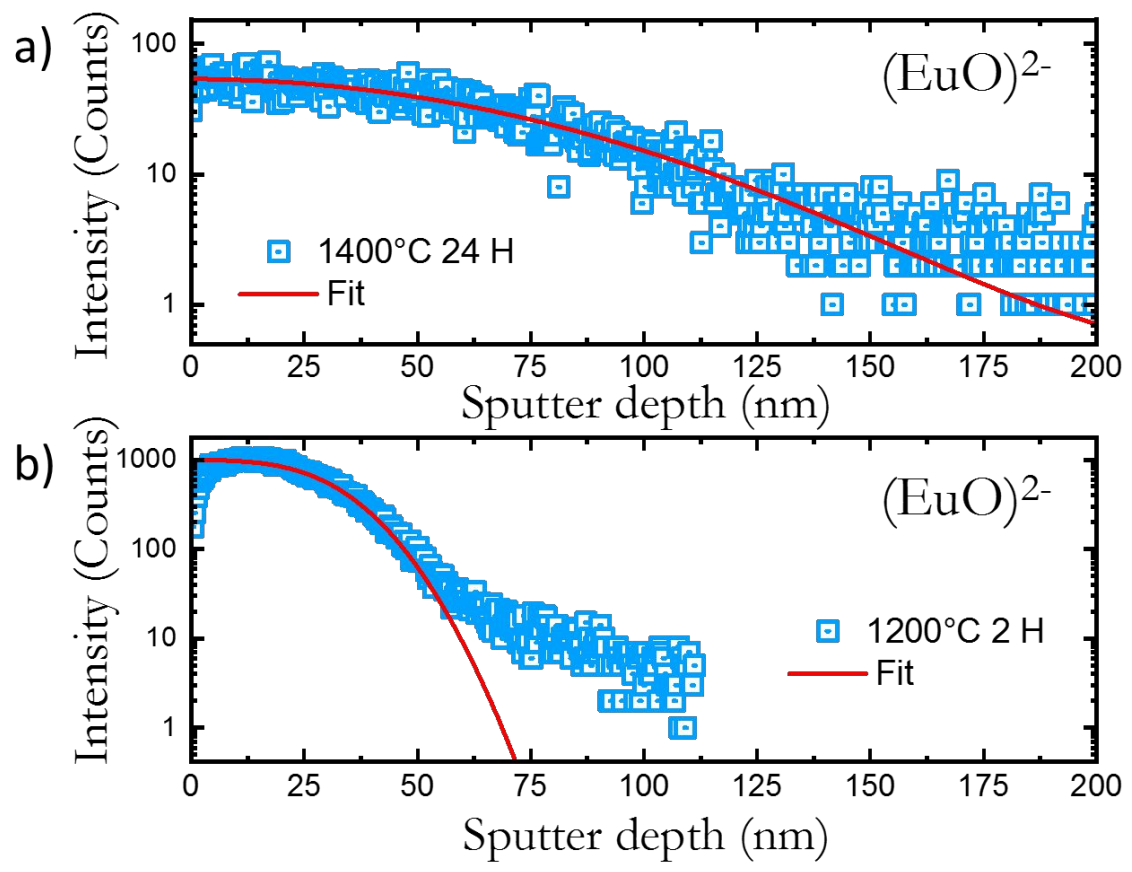

Figure 8: Higher resolution Eu-related TOF-SIMS signals of a thin ALD-grown $\mathrm{Eu}_{2} \mathrm{O}_{3}$ thin film on $Y_{2} \mathrm{SiO}_{5}$ for annealing at $1400^{\circ} \mathrm{C}$ for $2 \mathrm{~h}$ (a) and $1200^{\circ} \mathrm{C}$ for $24 \mathrm{~h}$ (b) respectively. Dots points are experimental data while solid lines are modelling using the diffusion equation (Eq. 1). One can note that a two-component contribution is visible for the $1200^{\circ} \mathrm{C}$ annealing sample. 


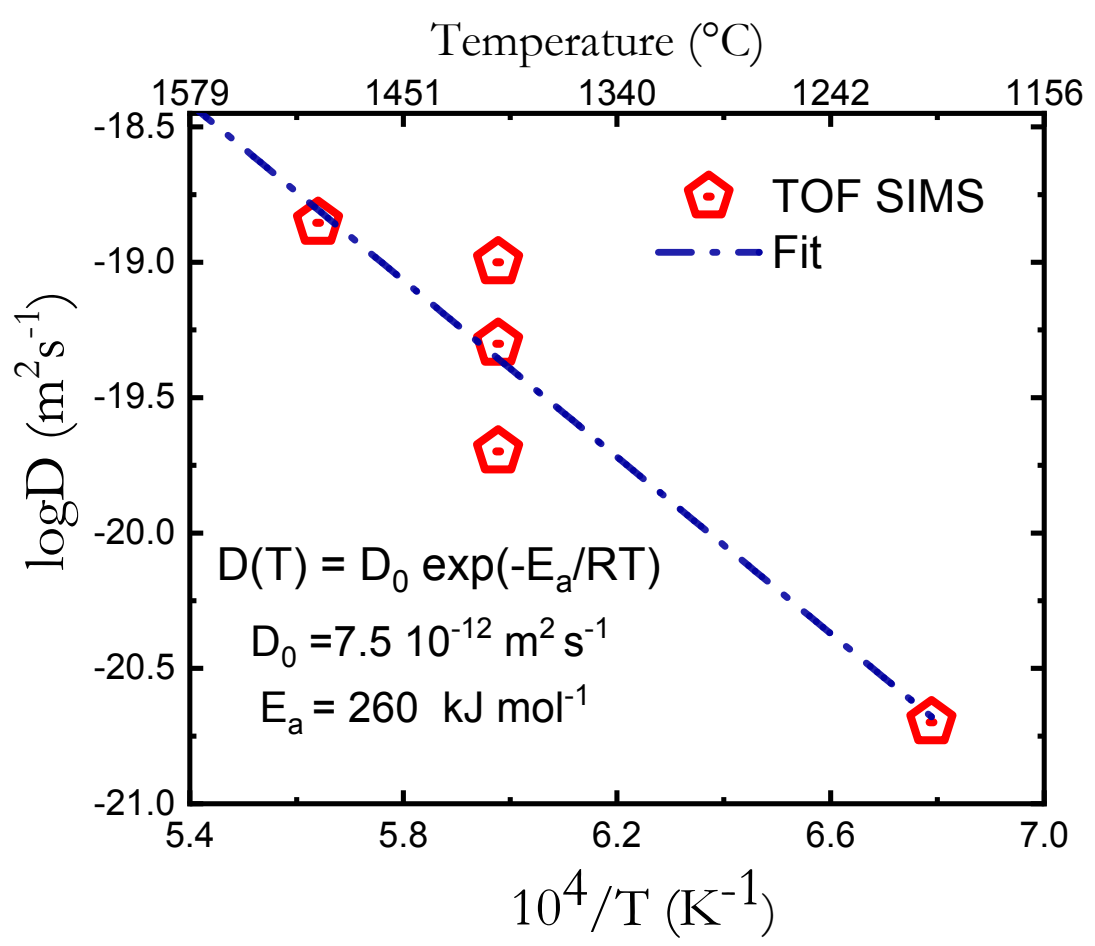

Figure 9: Arrhenius plot for Eu ${ }^{3+}$ diffusion in single crystal $\mathrm{Y}_{2} \mathrm{SiO}_{5}$ from TOF-SIMS measurements.

The line is a least-squares fit of the data. Arrhenius parameters extracted from the fit are presented in the figure.

Table 2: Diffusion parameters and measured diffusion coefficients. Example from the literature have been added for comparison.

\begin{tabular}{|c|c|c|c|c|c|}
\hline Crystal & $\begin{array}{c}\text { Doping } \\
\text { element }\end{array}$ & $\begin{array}{c}\text { Annealing } \\
\text { Temperature } \\
\left({ }^{\circ} \mathrm{C}\right)\end{array}$ & $\begin{array}{c}\text { Annealing } \\
\text { Time } \\
(\text { Hours })\end{array}$ & $\begin{array}{c}\text { Deference } \\
\left(\times 10^{-20} \mathrm{~m}^{2} \mathrm{~s}^{-1}\right)\end{array}$ & \\
\hline $\mathrm{Y}_{2} \mathrm{SiO}_{5}$ & $\mathrm{Eu}^{3+}$ & 1200 & 2 & 0.2 & This work \\
\hline
\end{tabular}




\begin{tabular}{|c|c|c|c|c|c|}
\hline $\mathrm{Y}_{2} \mathrm{SiO}_{5}$ & $\mathrm{Eu}^{3+}$ & 1400 & 2 & 10 & This work \\
\hline $\mathrm{Y}_{2} \mathrm{SiO}_{5}$ & $\mathrm{Eu}^{3+}$ & 1400 & 10 & 5.0 & This work \\
\hline $\mathrm{Y}_{2} \mathrm{SiO}_{5}$ & $\mathrm{Eu}^{3+}$ & 1400 & 24 & 2.2 & This work \\
\hline $\mathrm{Y}_{2} \mathrm{SiO}_{5}$ & $\mathrm{Eu}^{3+}$ & 1500 & 2 & 13.4 & This work \\
\hline $\mathrm{YVO}_{4}$ & $\mathrm{Nd}^{3+}$ & 1400 & 24 & 78 & 24 \\
\hline $\mathrm{Y}_{3} \mathrm{Al}_{5} \mathrm{O}_{12}$ & $\mathrm{Nd}^{3+}$ & 1200 & 25 & 0.26 & 54,55 \\
\hline $\mathrm{Y}_{3} \mathrm{Al}_{5} \mathrm{O}_{12}$ & $\mathrm{Yb}^{3+}$ & 1450 & 24.1 & 4.3 & 56 \\
\hline $\mathrm{Al}_{2} \mathrm{O}_{3}$ & $\mathrm{Tr}^{3+}$ & 1200 & 48 & 3 & \\
\hline
\end{tabular}

3.3. Optical properties of in-diffused europium ions

Eventually, we evaluated the optical properties of $\mathrm{Eu}^{3+}$ ions diffused from the ALD layer into the YSO substrate. To this end, spectral hole burning (SHB) experiments were performed in fluorescence detection mode on a sample annealed for $90 \mathrm{~h}$ at $1400^{\circ} \mathrm{C}$ (More information available in the supporting information file). SHB is a highly sensitive technique used to probe the material's crystalline quality. ${ }^{57,58}$ In this process, population is transferred from the ground state through the excited state of interest to a metastable states : the hyperfine levels ( Figure S5). Indeed, dopant properties, such as optical 
linewidth or nuclear spin lifetime, are strongly affected by crystal disorder (e.g. stacking fault, vacancies, mechanical strain, electric and magnetic noise). Moreover, the width of the spectral hole can provide information on the optical coherence lifetime since in the absence of power or laser broadening; it is expected to be twice the effective homogeneous linewidth. This linewidth is extremely sensitive to dynamical perturbation (moving charges, spin flip flop, two level systems) and act as an extremely sensitive strain and disorder probe and so SHB appears as a useful method to probe the surface. ${ }^{57}$ We used several high intensity burning pulses at a given frequency to resonantly excite the $\mathrm{Eu}^{3+}$ ions into their ${ }^{5} \mathrm{D}_{0}$ state and create a corresponding transparency window in the inhomogeneously broadened absorption line (for more detail see Figure S4 and S5). Then after a delay of a few ms for the $\mathrm{Eu}^{3+}$ fluorescence to vanish, a subsequent weaker laser pulse (probe laser) was sent to the sample. This probe pulse was frequency swept across the burned hole frequency $(-20 \mathrm{MHz},+20 \mathrm{MHz})$, with an acoustic optical modulator (AOM) to measure the excitation spectrum. Indeed in order to probe the pulse we worked in excitation mode by probing the change in the area of the red emission (i.e. the ${ }^{5} \mathrm{D}_{0} \rightarrow{ }^{7} \mathrm{~F}_{2}$ transition) as a function of the probe pulse wavelength. This change is due to the increased transparency at the hole frequency. First, we calibrated the experimental setup by burning a hole in a low $\mathrm{Eu}^{3+}$-doped bulk $\mathrm{Y}_{2} \mathrm{SiO}_{5}$ single crystal (Figure S6). This measurement is useful in order to estimate the additional 
broadening induced by the experimental conditions such as temperature, power broadening, laser linewidth and also laser stability. SHB signals recorded with this sequence present a hole FWHM of about $1.7 \mathrm{MHz}$ (Figure S6). This value is broader than the best values reported for $\mathrm{Eu}^{3+}: \mathrm{YSO}$ typically in the $\mathrm{kHz}$ range. ${ }^{59-61}$ In our experiment an additional experimental broadening arises from the linewidth of our laser $(300 \mathrm{kHz})$, the laser instability and the power broadening from this strongly focused configuration. SHB data was then recorded on the in-diffused sample (Fig. 10) for which the europium diffusion length $(2 \sqrt{D t})$ is estimated to $200 \mathrm{~nm}$. To select the emission contribution originating from the in-diffused ions at the surface, we first aligned the setup in order to maximize the laser reflection at the surface. Then, a spectral hole was burned at the central frequency of $580.041 \mathrm{~nm}$, from which, a promising hole linewidth as narrow as $4 \mathrm{MHz}$ was obtained. This is about twice that of the low $\mathrm{Eu}^{3+}$ doped bulk reference sample. This difference is likely related to the higher Eu concentration at the surface (Figure 8). To discard any contribution trace $\mathrm{Eu}^{3+}$ ions in the YSO substrate also absorbing at the same central frequency, a second SHB experiment was performed at a slightly different wavelength of $580.057 \mathrm{~nm}$, which is $15 \mathrm{GHz}$ away from the central position of the inhomogeneous line. According to a study on an $\mathrm{Eu}^{3+}: \mathrm{YSO}$ single crystal, the inhomogeneous linewidth is expected to linearly increase with $\mathrm{Eu}^{3+}$ concentration of about $21 \mathrm{GHz} / \%{ }^{62}$ This concentration dependency suggest that the second SHB experiment are 
perform on $\mathrm{Eu}^{3+}$ ions closer to the surface. At this wavelength a narrow hole can still be burned but with a larger FWHM (6 MHz) and shallower than the previous one. One possibility to explain the larger broadening in the diffused area compared to the reference, could be that an increase in concentration leads to some disorder in the structure that generates additional dynamical dephasing processes like Two Level System (TLS). ${ }^{23}$ This disorder arises from possible variations of the local stoichiometry or interstitial defects since cation exchange occurs between two different material, $\mathrm{Eu}_{2} \mathrm{O}_{3}$ and $\mathrm{Y}_{2} \mathrm{SiO}_{5}$ respectively. More high-resolution spectroscopy measurements are required to determine the predominant dephasing mechanism. Anyway, this work demonstrates that RE ions can be spatially localized near the surface by a two-step process based on ALD deposition and annealing post treatment under appropriate conditions, while retaining their excellent optical properties. For various applications in quantum technologies, frequency-resolved optical pumping (i.e. spectral hole burning) appears as an essential preparation step. This step requires the possibility to address selectively by optical pumping each hyperfine sublevel. According to the hyperfine splitting of $\mathrm{Eu}^{63}$, this implies that the spectral hole FWHM has to be narrower than $10 \mathrm{MHz}$. Therefore, an important issue of this work, is the demonstration of efficient burning of a sufficiently narrow hole for the in-diffused Eu:YSO. The measured FWHM of the burned hole is about 4.2 MHz, which remains suitable for the selective optical pumping. This 
narrow FWHM suggests that Eu ions substitute to $Y$ ions without significant distortion of the cation site as an important broadening of the hole would be expected in the case of disordered systems. For example, typical FWHM of SHB in Eu-doped silicate glasses are one order of magnitude broader, typically around $30-50 \mathrm{MHz} .{ }^{64}$ Another relevant comparison may be done with thin films. Indeed, thin films constitute an alternative approach that could possibly allow one to benefit from the flexibility of multi-layers of variable thicknesses with spatially localized emitters. Currently, the only achievement of hole burning on films has been obtained on $3 \mu \mathrm{m}$-thick MOCVD-grown films of $\mathrm{Eu}: \mathrm{Y}_{2} \mathrm{O}_{3}$ deposited on sapphire. ${ }^{65}$ At the same temperature, the FWHM of the spectral hole was found to be significantly broader, around $30 \mathrm{MHz}$, indicating that crystalline quality of the film needs to be significantly improved before becoming an alternative to single crystal. 


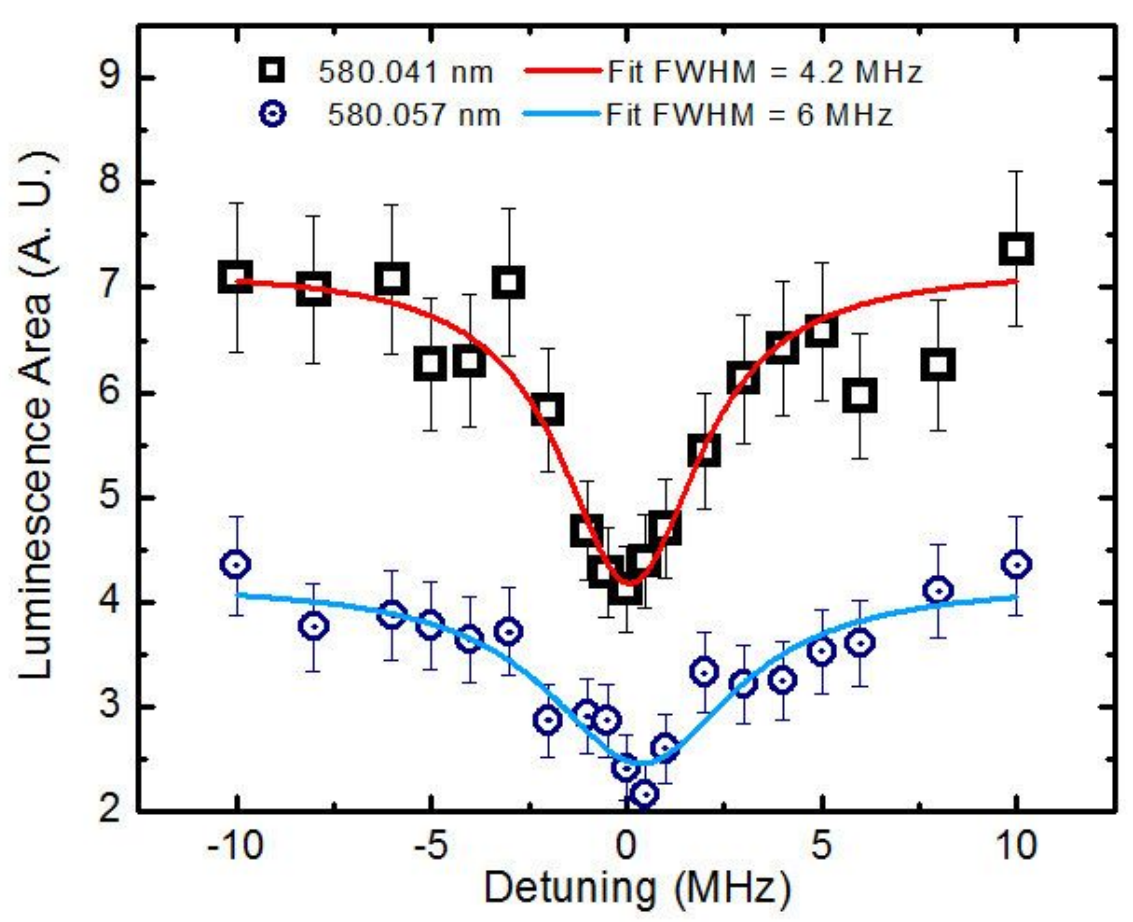

Figure 10. Fluorescence-detection of spectral holes burned on an $\mathrm{ALD}-\mathrm{Eu}_{2} \mathrm{O}_{3}$ thin film on $\mathrm{Y}_{2} \mathrm{SiO}_{5}$

annealed 90 hours at $1400^{\circ} \mathrm{C}$. Measurements at two different wavelengths of the inhomogeneous

line are presented and the linewidth is given. Curves are vertically translated for better clarity.

\section{Conclusion}

In this work, we studied the ability of the ALD technique to spatially localize rare-earth ion emitters with good optical properties. In particular, we evaluated $\mathrm{Eu}^{3+}$ ion diffusion from few nanometers-thin $\mathrm{Eu}_{2} \mathrm{O}_{3}$ film grown by ALD into a polycrystalline $\mathrm{Y}_{2} \mathrm{O}_{3}$ film or into a single crystal $\mathrm{Y}_{2} \mathrm{SiO}_{5}$ substrate after thermal annealing in the $900-1400{ }^{\circ} \mathrm{C}$ range. While such high temperature post-treatments are essential to improve the crystallinity of thin ALD films, they lead to a partial 
loss of RE ion localization. On the other hand, this behavior can be harnessed to locally diffuse emitters in the close proximity of the crystal surface.

Based on RBS and TOF-SIMS analyses, we observed that $\mathrm{Eu}^{3+}$ diffusion into polycrystalline $\mathrm{Y}_{2} \mathrm{O}_{3}$ becomes efficient at lower temperatures $\left(900^{\circ} \mathrm{C}\right)$ in comparison to single crystal $\mathrm{YSO}$ $\left(1200^{\circ} \mathrm{C}\right)$. This is attributed to the presence of grain boundaries that increase diffusion kinetics. Diffusion coefficients of about $4 \times 10^{-21}$ and $2 \times 10^{-20} \mathrm{~m}^{2} . \mathrm{s}^{-1}$ at $950^{\circ} \mathrm{C}$ and $1000{ }^{\circ} \mathrm{C}$ respectively in poly $-\mathrm{Y}_{2} \mathrm{O}_{3}$ and $2 \times 10^{-21}$ and $10 \times 10^{-20} \mathrm{~m}^{2} \cdot \mathrm{s}^{-1}$ at 1200 and $1400{ }^{\circ} \mathrm{C}$ respectively were measured in a YSO single crystal.

This investigation indicates that, based on the nanometer-scale deposition ability of ALD associated with an appropriate thermal annealing, rare-earth oxide materials can be engineered with specific nanostructures in which dopant localization is well controlled. We eventually demonstrate that excellent optical properties are retained for such in-diffused near-surface RE ions in YSO. Spectral hole burning showed values as low as $4 \mathrm{MHz}$ which could be improved by changing the composition of the top $\mathrm{Eu}_{2} \mathrm{O}_{3}$ layer that may lead to too high $\mathrm{Eu}^{3+}$ concentration close vicinity to the surface. This approach could provide an attractive alternative to rare-earth ion implantation and will be further explored in QTs applications such as quantum memories and 
quantum sensors. Finally, this cation exchange method is versatile and can be applied to a large range of materials and doping elements (e.g. transition metal).

\section{Supporting Information:}

Detail on oxygen content measured by $\mathrm{NRA}$; on the $\mathrm{SiO}_{2}$ thickness measured by ellipsometry ; comparison of Eu diffusion profile deduced from TOF-SIMS and RBS; on the hole burning experimental setup; on energy level of Europium and on hole burning on $\mathrm{Eu}: \mathrm{Y}_{2} \mathrm{SiO}_{5}$ single crystal.

\section{Acknowledgements:}

We acknowledge the French EMIR-A network for provision of irradiation beam time using the SAFIR facility and the financial support of the Paris network on quantum technologies (SIRTEQ), This project has received funding from the European Union Horizon 2020 research and innovation program under grant agreement no. 820391 (SQUARE) and no. 712721 (NANOQTECH).

\section{References}


(1) Goldner, P.; Ferrier, A.; Guillot-Noël, O. Rare Earth-Doped Crystals for Quantum Information Processing. In Handbook on the Physics and Chemistry of Rare Earths; Bünzli, J.-C. G., Pecharsky, V. K., Eds.; Elsevier, North Holland: Amsterdam, 2015; Vol. 46, pp 1-78.

(2) Korzenski, M. B.; Lecoeur, Ph.; Mercey, B.; Chippaux, D.; Raveau, B.; Desfeux, R. PLD-Grown $\mathrm{Y}_{2} \mathrm{O}_{3}$ Thin Films from Y Metal: An Advantageous Alternative to Films Deposited from Yttria. Chem. Mater. 2000, 12 (10), 3139-3150. https://doi.org/10.1021/cm001094e.

(3) Singh, M. K.; Prakash, A.; Wolfowicz, G.; Wen, J.; Huang, Y.; Rajh, T.; Awschalom, D. D.; Zhong, T.; Guha, S. Epitaxial Er-Doped $\mathrm{Y}_{2} \mathrm{O}_{3}$ on Silicon for Quantum Coherent Devices. APL Mater. 2020, 8 (3), 031111. https://doi.org/10.1063/1.5142611.

(4) Andriamiadamanana, C.; Ibanez, A.; Ferrier, A.; Joudrier, A.-L.; Lombez, L.; Liotaud, M.; Guillemoles, J.-F.; Pellé, F. Erbium-Doped Yttria Thin Films Prepared by Metal Organic Decomposition for up-Conversion. Thin Solid Films 2013, 537, 42-48. https://doi.org/10.1016/j.tsf.2013.04.093.

(5) Rubio, E. J.; Atuchin, V. V.; Kruchinin, V. N.; Pokrovsky, L. D.; Prosvirin, I. P.; Ramana, C. V. Electronic Structure and Optical Quality of Nanocrystalline $\mathrm{Y}_{2} \mathrm{O}_{3}$ Film Surfaces and Interfaces on Silicon. J. Phys. Chem. C 2014, 118 (25), 13644-13651. https://doi.org/10.1021/jp502876r.

(6) Zhao, B.; Mattelaer, F.; Rampelberg, G.; Dendooven, J.; Detavernier, C. Thermal and PlasmaEnhanced Atomic Layer Deposition of Yttrium Oxide Films and the Properties of Water Wettability. ACS Appl. Mater. Interfaces 2020, 12 (2), 3179-3187. https://doi.org/10.1021/acsami.9b18412.

(7) de Rouffignac, P.; Park, J.-S.; Gordon, R. G. Atomic Layer Deposition of $\mathrm{Y}_{2} \mathrm{O}_{3}$ Thin Films from Yttrium Tris(N,N'-Diisopropylacetamidinate) and Water. Chem. Mater. 2005, 17, 4808-4814.

(8) Guo, H.; Zhang, W.; Lou, L.; Brioude, A.; Mugnier, J. Structure and Optical Properties of Rare Earth Doped $\mathrm{Y}_{2} \mathrm{O}_{3}$ Waveguide Films Derived by Sol-Gel Process. Thin Solid Films 2004, 458 (1), 274-280. https://doi.org/10.1016/j.tsf.2003.12.059.

(9) Dibos, A. M.; Raha, M.; Phenicie, C. M.; Thompson, J. D. Atomic Source of Single Photons in the Telecom Band. Phys. Rev. Lett. 2018, 120 (24), 243601. https://doi.org/10.1103/PhysRevLett.120.243601.

(10) Zhong, T.; Kindem, J. M.; Bartholomew, J. G.; Rochman, J.; Craiciu, I.; Miyazono, E.; Bettinelli, M.; Cavalli, E.; Verma, V.; Nam, S. W.; et al. Nanophotonic Rare-Earth Quantum Memory with Optically Controlled Retrieval. Science 2017, 357 (6358), 1392-1395. https://doi.org/10.1126/science.aan5959.

(11) Tielrooij, K. J.; Orona, L.; Ferrier, A.; Badioli, M.; Navickaite, G.; Coop, S.; Nanot, S.; Kalinic, B.; Cesca, T.; Gaudreau, L.; et al. Electrical Control of Optical Emitter Relaxation Pathways Enabled by Graphene. Nat. Phys. 2015, 11 (3), 281-287. https://doi.org/10.1038/nphys3204.

(12) Casabone, B.; Benedikter, J.; Hümmer, T.; Oehl, F.; Lima, K. de O.; Hänsch, T. W.; Ferrier, A.; Goldner, P.; Riedmatten, H. de; Hunger, D. Cavity-Enhanced Spectroscopy of a Few-Ion Ensemble in $\mathrm{Eu}^{3+}: \mathrm{Y}_{2} \mathrm{O}_{3}$. New J. Phys. 2018, 20 (9), 095006. https://doi.org/10.1088/1367-2630/aadf68.

(13) Wolf, T.; Neumann, P.; Nakamura, K.; Sumiya, H.; Ohshima, T.; Isoya, J.; Wrachtrup, J. Subpicotesla Diamond Magnetometry. Phys. Rev. X 2015, 5 (4), 041001. https://doi.org/10.1103/PhysRevX.5.041001.

(14) Hoang, J.; Schwartz, R. N.; Wang, K. L.; Chang, J. P. Er ${ }^{3+}$ Interlayer Energy Migration as the Limiting Photoluminescence Quenching Factor in Nanostructured $\mathrm{Er}^{3+}: \mathrm{Y}_{2} \mathrm{O}_{3}$ Thin Films. J. Appl. Phys. 2012, 112 (2), 023116. https://doi.org/10.1063/1.4737793.

(15) Groot-Berning, K.; Kornher, T.; Jacob, G.; Stopp, F.; Dawkins, S. T.; Kolesov, R.; Wrachtrup, J.; Singer, K.; Schmidt-Kaler, F. Deterministic Single-Ion Implantation of Rare-Earth lons for Nanometer-Resolution Color-Center Generation. Phys. Rev. Lett. 2019, 123 (10), 106802. https://doi.org/10.1103/PhysRevLett.123.106802. 
(16) van Dam, S. B.; Walsh, M.; Degen, M. J.; Bersin, E.; Mouradian, S. L.; Galiullin, A.; Ruf, M.; IJspeert, M.; Taminiau, T. H.; Hanson, R.; et al. Optical Coherence of Diamond Nitrogen-Vacancy Centers Formed by Ion Implantation and Annealing. Phys. Rev. B 2019, 99 (16), 161203. https://doi.org/10.1103/PhysRevB.99.161203.

(17) Kukharchyk, N.; Shvarkov, S.; Probst, S.; Xia, K.; Becker, H.-W.; Pal, S.; Markmann, S.; Kolesov, R.; Siyushev, P.; Wrachtrup, J.; et al. Nanoscale Nonlinear Effects in Erbium-Implanted Yttrium Orthosilicate. J. Lumin. 2016, 177, 266-274. https://doi.org/10.1016/j.jlumin.2016.05.010.

(18) Kolesov, R.; Xia, K.; Reuter, R.; Stöhr, R.; Zappe, A.; Meijer, J.; Hemmer, P. R.; Wrachtrup, J. Optical Detection of a Single Rare-Earth Ion in a Crystal. Nat. Commun. 2012, 3 (1), 1029. https://doi.org/10.1038/ncomms2034.

(19) Proslier, T.; Becker, N. G.; Pellin, M. J.; Klug, J.; Elam, J. W. Controlling the Emissive Properties of Materials-Improved Lasers and Upconversion Materials. US8518179B1, August 27, 2013.

(20) Rönn, J.; Karvonen, L.; Kauppinen, C.; Perros, A. P.; Peyghambarian, N.; Lipsanen, H.; Säynätjoki, A.; Sun, Z. Atomic Layer Engineering of Er-Ion Distribution in Highly Doped $\mathrm{Er}_{\mathrm{Al}} \mathrm{Al}_{2} \mathrm{O}_{3}$ for Photoluminescence Enhancement. ACS Photonics 2016, 3 (11), 2040-2048. https://doi.org/10.1021/acsphotonics.6b00283.

(21) Scarafagio, M.; Tallaire, A.; Tielrooij, K.-J.; Cano, D.; Grishin, A.; Chavanne, M.-H.; Koppens, F. H. L.; Ringuedé, A.; Cassir, M.; Serrano, D.; et al. Ultrathin Eu- and Er-Doped $\mathrm{Y}_{2} \mathrm{O}_{3}$ Films with Optimized Optical Properties for Quantum Technologies. J. Phys. Chem. C 2019, 123 (21), 1335413364. https://doi.org/10.1021/acs.jpcc.9b02597.

(22) Welinski, S.; Thiel, C. W.; Dajczgewand, J.; Ferrier, A.; Cone, R. L.; Macfarlane, R. M.; Chanelière, T.; Louchet-Chauvet, A.; Goldner, P. Effects of Disorder on Optical and Electron Spin Linewidths in $\mathrm{Er}^{3+}, \mathrm{Sc}^{3+}: \mathrm{Y}_{2} \mathrm{SiO}_{5}$. Opt. Mater. 2017, 63, 69-75. https://doi.org/10.1016/j.optmat.2016.09.039.

(23) Flinn, G. P.; Ganem, J.; Jones', M. L.; Meltzer, R. S.; Macfarlane, R. M. Sample Dependant Optical Dephasing in Bulk Crystalline Samles of $\mathrm{Y}_{2} \mathrm{O}_{3}$ :Eu. Phys. Rev. B 1994, 49, 5821.

(24) Cherniak, D. J. Rare Earth Element and Gallium Diffusion in Yttrium Aluminum Garnet. Phys. Chem. Miner. 1998, 26 (2), 156-163. https://doi.org/10.1007/s002690050172.

(25) Moya, E. G.; Moya, F.; Lesage, B.; LoudjanP, M. I.; Grattepainc, C. Yttrium Diffusion in A-Alumina Single Crystal. J. Eur. Ceram. 1998, 18, 591-594.

(26) Hettrick, S. J.; Wilinson, S.; Sheperd, D. P. Neodymium and Gadolinium Diffusion in Yttrium Vanadate. J. Opt. Soc. Am. B 2002, 19 (1), 33.

(27) Brady, J. B.; Cherniak, D. J. Diffusion in Minerals: An Overview of Published Experimental Diffusion Data. Rev. Mineral. Geochem. 2010, 72 (1), 899-920. https://doi.org/10.2138/rmg.2010.72.20.

(28) Fujioka, K.; Sugiyama, A.; Fujimoto, Y.; Kawanaka, J.; Miyanaga, N. Ion Diffusion at the Bonding Interface of Undoped YAG/Yb:YAG Composite Ceramics. Opt. Mater. 2015, 46, 542-547. https://doi.org/10.1016/j.optmat.2015.05.023.

(29) Schmidt, R. V.; Kaminow, I. P. Metal-Diffused Optical Waveguides in LiNbO 3 . Appl. Phys. Lett. 1974, 25, 458.

(30) Wang, T.-J.; Chen, B.-W.; Chen, P.-K.; Chen, C.-H. Er/Si Interdiffusion Effect on Photoluminescent Properties of Erbium Oxide/Silicon Oxide Films Deposited on Silicon. J. Lumin. 2017, 192, 10651071. https://doi.org/10.1016/j.jlumin.2017.08.050.

(31) Adachi, G.; Imanaka, N. The Binary Rare Earth Oxides. Chem. Rev. 1998, 98 (4), 1479-1514. https://doi.org/10.1021/cr940055h.

(32) Ishibashi, H.; Shimomoto, K.; Nakahigashi, K. Electron Density Distribution and Chemical Bonding of $\mathrm{Ln}_{2} \mathrm{O}_{3}(\mathrm{Ln}=\mathrm{Y}, \mathrm{Tm}, \mathrm{Yb})$ from Powder X-Ray Diffraction Data by the Maximum-Entropy Method. J. Phys. Chem. Solids 1994, 55 (9), 809-814. https://doi.org/10.1016/0022-3697(94)90004-3. 
(33) Ferrier, A.; Tumino, B.; Goldner, Ph. Variations in the Oscillator Strength of the ${ }^{7} F_{0} \rightarrow{ }^{5} D_{0}$ Transition in $\mathrm{Eu}^{3+}: \mathrm{Y}_{2} \mathrm{SiO}_{5}$ Single Crystals. J. Lumin. 2016, 170, 406-410. https://doi.org/10.1016/j.jlumin.2015.07.026.

(34) Denault, K. A.; Brgoch, J.; Kloß, S. D.; Gaultois, M. W.; Siewenie, J.; Page, K.; Seshadri, R. Average and Local Structure, Debye Temperature, and Structural Rigidity in Some Oxide Compounds Related to Phosphor Hosts. ACS Appl. Mater. Interfaces 2015, 7 (13), 7264-7272. https://doi.org/10.1021/acsami.5b00445.

(35) Díaz, B.; Härkönen, E.; Światowska, J.; Maurice, V.; Seyeux, A.; Marcus, P.; Ritala, M. LowTemperature Atomic Layer Deposition of $\mathrm{Al}_{2} \mathrm{O}_{3}$ Thin Coatings for Corrosion Protection of Steel: Surface and Electrochemical Analysis. Corros. Sci. 2011, 53 (6), 2168-2175. https://doi.org/10.1016/j.corsci.2011.02.036.

(36) Härkönen, E.; Díaz, B.; Światowska, J.; Maurice, V.; Seyeux, A.; Vehkamäki, M.; Sajavaara, T.; Fenker, M.; Marcus, P.; Ritala, M. Corrosion Protection of Steel with Oxide Nanolaminates Grown by Atomic Layer Deposition. J. Electrochem. Soc. 2011, 158 (11), C369. https://doi.org/10.1149/2.061111jes.

(37) Díaz, B.; Światowska, J.; Maurice, V.; Seyeux, A.; Normand, B.; Härkönen, E.; Ritala, M.; Marcus, P. Electrochemical and Time-of-Flight Secondary Ion Mass Spectrometry Analysis of Ultra-Thin Metal Oxide $\left(\mathrm{Al}_{2} \mathrm{O}_{3}\right.$ and $\left.\mathrm{Ta}_{2} \mathrm{O}_{5}\right)$ Coatings Deposited by Atomic Layer Deposition on Stainless Steel. Electrochimica Acta 2011, 56 (28), 10516-10523. https://doi.org/10.1016/j.electacta.2011.02.074.

(38) Potts, S. E.; Schmalz, L.; Fenker, M.; Díaz, B.; Światowska, J.; Maurice, V.; Seyeux, A.; Marcus, P.; Radnóczi, G.; Tóth, L.; et al. M. Ultra-Thin Aluminium Oxide Films Deposited by Plasma-Enhanced Atomic Layer Deposition for Corrosion Protection. J. Electrochem. Soc. 2011, 158 (5), C132. https://doi.org/10.1149/1.3560197.

(39) Mayer, M. Improved Physics in SIMNRA 7. Nucl. Instrum. Methods Phys. Res. Sect. B Beam Interact. Mater. At. 2014, 332, 176-180. https://doi.org/10.1016/j.nimb.2014.02.056.

(40) Scarafagio, M.; Tallaire, A.; Chavanne, M.-H.; Cassir, M.; Ringuedé, A.; Serrano, D.; Goldner, P.; Ferrier, A. Improving the Luminescent Properties of Atomic Layer Deposition Eu: $\mathrm{Y}_{2} \mathrm{O}_{3}$ Thin Films through Optimized Thermal Annealing. Phys. Status Solidi A 2020, 1900909. https://doi.org/10.1002/pssa.201900909.

(41) Shannon, R. D.; Prewitt, C. T. Effective Ionic Radii in Oxides and Fluorides. Acta Crystallogr. B 1969, 25 (5), 925-946. https://doi.org/10.1107/S0567740869003220.

(42) Mehrer, H. Diffusion in Solids : Fundamentals, Methods, Materials, Diffusion-Controlled Processes; Springer series in Solid State Science; Springer-Verlag Berlin and Heidelberg GmbH \& Co. K, 2009.

(43) Gaboriaud, R. J. Self-Diffusion of Yttrium in Monocrystalline Yttrium Oxide: $\mathrm{Y}_{2} \mathrm{O}_{3}$. J. Solid State Chem. 1980, pp 252-261.

(44) Zhou, B.; Shi, B.; Jin, D.; Liu, X. Controlling Upconversion Nanocrystals for Emerging Applications. Nat. Nanotechnol. 2015, 10 (11), 924-936. https://doi.org/10.1038/nnano.2015.251.

(45) Wang, F.; Deng, R.; Wang, J.; Wang, Q.; Han, Y.; Zhu, H.; Chen, X.; Liu, X. Tuning Upconversion through Energy Migration in Core-Shell Nanoparticles. Nat. Mater. 2011, 10 (12), 968-973. https://doi.org/10.1038/nmat3149.

(46) Wen, S.; Zhou, J.; Zheng, K.; Bednarkiewicz, A.; Liu, X.; Jin, D. Advances in Highly Doped Upconversion Nanoparticles. Nat. Commun. 2018, 9 (1), 1-12. https://doi.org/10.1038/s41467018-04813-5.

(47) Clausen, C.; Usmani, I.; Bussières, F.; Sangouard, N.; Afzelius, M.; Riedmatten, H. de; Gisin, N. Quantum Storage of Photonic Entanglement in a Crystal. Nature 2011, 469 (7331), 508-511. https://doi.org/10.1038/nature09662. 
(48) Bussières, F.; Clausen, C.; Tiranov, A.; Korzh, B.; Verma, V. B.; Nam, S. W.; Marsili, F.; Ferrier, A.; Goldner, P.; Herrmann, H.; et al. Quantum Teleportation from a Telecom-Wavelength Photon to a Solid-State Quantum Memory. Nat. Photonics 2014, 8 (10), 775-778. https://doi.org/10.1038/nphoton.2014.215.

(49) Ortu, A.; Tiranov, A.; Welinski, S.; Fröwis, F.; Gisin, N.; Ferrier, A.; Goldner, P.; Afzelius, M. Simultaneous Coherence Enhancement of Optical and Microwave Transitions in Solid-State Electronic Spins. Nat. Mater. 2018, 17 (8), 671-675. https://doi.org/10.1038/s41563-018-0138-x.

(50) Harrison, L. G. Influence of Dislocations on Diffusion Kinetics in Solids with Particular Reference to the Alkali Halides. Trans. Faraday Soc. 1961, 57, 1191. https://doi.org/10.1039/tf9615701191.

(51) Moya, E. G.; Moya, F.; Sami, A.; Juvé, D.; Tréheux, D.; Grattepain, C. Diffusion of Chromium in Alumina Single Crystals. Philos. Mag. A 1995, 72 (4), 861-870. https://doi.org/10.1080/01418619508239939.

(52) Sabioni, A. C. S.; Huntz, A. M.; Daniel, A. M. J. M.; Macedo, W. A. A. Measurement of Iron SelfDiffusion in Hematite Single Crystals by Secondary Ion-Mass Spectrometry (SIMS) and Comparison with Cation Self-Diffusion in Corundum-Structure Oxides. Philos. Mag. 2005, 85 (31), 3643-3658. https://doi.org/10.1080/14786430500323795.

(53) Carlson, W. D. Rates and Mechanism of Y, REE, and Cr Diffusion in Garnet. Am. Mineral. 2012,97 (10), 1598-1618. https://doi.org/10.2138/am.2012.4108.

(54) Marquardt, K.; Ramasse, Q. M.; Kisielowski, C.; Wirth, R. Diffusion in Yttrium Aluminium Garnet at the Nanometer-Scale: Insight into the Effective Grain Boundary Width. Am. Mineral. 2011, 96 (10), 1521-1529. https://doi.org/10.2138/am.2011.3625.

(55) Marquardt, K.; Petrishcheva, E.; Abart, R.; Gardés, E.; Wirth, R.; Dohmen, R.; Becker, H.-W.; Heinrich, W. Volume Diffusion of Ytterbium in YAG: Thin-Film Experiments and Combined TEMRBS Analysis. Phys. Chem. Miner. 2010, 37 (10), 751-760. https://doi.org/10.1007/s00269-0100373-4.

(56) Legros, C.; Lesage, B.; Borchardt, G.; Kilo, M.; Jomard, F. Lanthanide Diffusion in Single Crystalline and Polycrystalline Pure or Yttrium Doped Alpha-Alumina. Defect Diffus. Forum 2005, 237-240, 432-437. https://doi.org/10.4028/www.scientific.net/DDF.237-240.432.

(57) Bartholomew, J. G.; de Oliveira Lima, K.; Ferrier, A.; Goldner, P. Optical Line Width Broadening Mechanisms at the $10 \mathrm{KHz}$ Level in $\mathrm{Eu}^{3+}: \mathrm{Y}_{2} \mathrm{O}_{3}$ Nanoparticles. Nano Lett. 2017, 17 (2), $778-787$. https://doi.org/10.1021/acs.nanolett.6b03949.

(58) Lutz, T.; Veissier, L.; Thiel, C. W.; Woodburn, P. J. T.; Cone, R. L.; Barclay, P. E.; Tittel, W. Effects of Fabrication Methods on Spin Relaxation and Crystallite Quality in Tm-Doped $\mathrm{Y}_{3} \mathrm{Al}_{5} \mathrm{O}_{12}$ Powders Studied Using Spectral Hole Burning. Sci. Technol. Adv. Mater. 2016, 17 (1), 63-70. https://doi.org/10.1080/14686996.2016.1148528.

(59) Oswald, R.; Hansen, M. G.; Wiens, E.; Nevsky, A. Yu.; Schiller, S. Characteristics of Long-Lived Persistent Spectral Holes in $\mathrm{Eu}_{\mathrm{Y}} \mathrm{SiO}_{5}$ at 1.2 K. Phys. Rev. A 2018, 98 (6), 062516. https://doi.org/10.1103/PhysRevA.98.062516.

(60) Gobron, O.; Jung, K.; Galland, N.; Predehl, K.; Le Targat, R.; Ferrier, A.; Goldner, P.; Seidelin, S.; Le Coq, Y. Dispersive Heterodyne Probing Method for Laser Frequency Stabilization Based on Spectral Hole Burning in Rare-Earth Doped Crystals. Opt. Express 2017, 25 (13), 15539. https://doi.org/10.1364/OE.25.015539.

(61) Zhang, S.; Galland, N.; Lučić, N.; Le Targat, R.; Ferrier, A.; Goldner, P.; Fang, B.; Le Coq, Y.; Seidelin, S. Inhomogeneous Response of an Ion Ensemble from Mechanical Stress. Phys. Rev. Res. 2020, 2 (1), 013306. https://doi.org/10.1103/PhysRevResearch.2.013306.

(62) Könz, F.; Sun, Y.; Thiel, C. W.; Cone, R. L.; Equall, R. W.; Hutcheson, R. L.; Macfarlane, R. M. Temperature and Concentration Dependence of Optical Dephasing, Spectral-Hole Lifetime, and 
Anisotropic Absorption in $\mathrm{Eu}^{3+}: \mathrm{Y}_{2} \mathrm{SiO}_{5}$. Phys. Rev. B 2003, 68 (8), 085109. https://doi.org/10.1103/PhysRevB.68.085109.

(63) Arcangeli, A.; Lovrić, M.; Tumino, B.; Ferrier, A.; Goldner, P. Spectroscopy and Coherence Lifetime Extension of Hyperfine Transitions in ${ }^{151} \mathrm{Eu}^{3+}: \mathrm{Y}_{2} \mathrm{SiO}_{5}$. Phys. Rev. B 2014, 89 (18), 184305. https://doi.org/10.1103/PhysRevB.89.184305.

(64) MacFarlane, R. M.; Shelby, R. M. Homogeneous Line Broadening of Optical Transitions of lons and Molecules in Glasses. J. Lumin. 1987, 36 (4-5), 179-207. https://doi.org/10.1016/00222313(87)90194-3.

(65) Flinn, G. P.; Jang, K. W.; Ganem, J.; Jones, M. L.; Meltzer, R. S.; Macfarlane, R. M. Anomalous Optical Dephasing in Crystalline $\mathrm{Y}_{2} \mathrm{O}_{3}$ : Eü3. J. Lumin. 1994, 58 (1), 374-379.

https://doi.org/10.1016/0022-2313(94)90441-3. 


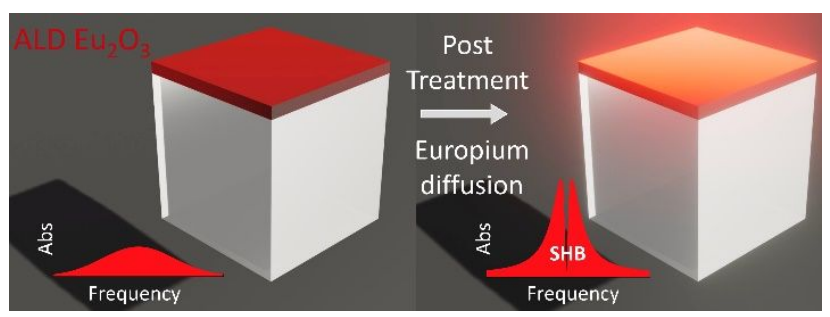

TOC Graphic

10

11

12

13

14

15

16

17

18

19

20

21

22

23

24

25

26

27

28

29

30

31

32

33

34

35

36

37

38

39

40

41

42

43

44

45

46

47

48

49

50

51

52

53

54

55

56

57

58

59

60

ACS Paragon Plus Environment 